\title{
Choroidal Vessel Wall: Hypercholesterolaemia-Induced Dysfunction and Potential Role of Statins
}

\author{
J.M. Ramírez, J.J. Salazar, R. de Hoz, \\ B. Rojas, B.I. Gallego, A.I. Ramírez and A. Triviño
}

Additional information is available at the end of the chapter

http://dx.doi.org/10.5772/47794

\section{Introduction}

The choroid, the most important vascular tissue of the eye, is made up of vascular layers of descending thicknesses, from the large-sized choroidal vessels close to the sclera, to the choriocapillaris underlying the retina. Some $85 \%$ of the blood flow of the eye circulates through the choroidal vessels. The most important functions of the choroid include the regulation of eye temperature and the nutrient supply to the outer retinal layers, in which ischaemia would seriously compromise visual function. The integrity of the cells of the vascular endothelium and of the smooth-muscle cells therefore proves essential to maintain the choroidal flow [1].

The rise of the plasma-cholesterol levels is known to be accompanied by an overexpression of monocytic chemotactic protein-1 (MCP-1) by the macrophages and vascular smoothmuscle cells, which play a pivotal role in the development of fatty streaks [2]. In this way, an endothelium altered by hypercholesterolaemia leads to a pre-thrombosis state that begins with the aggregation of platelets. This is contributed to by aggregates that accumulate in the intima of the arteriolar wall as a result of the interaction of low-density lipoprotein (LDL) with the extracellular matrix [3,4]. Endothelial dysfunction precedes atherosclerosis, which is characterized by the expression of two adhesion molecules, the vascular adhesion molecule-1 (VCAM-1) and the inter-cellular adhesion molecule-1 (ICAM-1). Both participate in the adhesion and extravasation of the monocytes into the subendothelial space, where they are transformed into macrophages. These subendothelial macrophages participate in transforming the LDL into highly oxidized LDL (oxLDL), which after being taken up by the macrophages contributes to the formation of foam cells [5] such as those seen in the large cho- 
roidal vessels and in the suprachoroid of hypercholesterolaemic rabbits [6]. The saturation of the foam cells leads to their death and the release of toxic products such as esterified and oxidized cholesterol, a scenario that inflicts greater endothelial damage and encourages the progression of the atherosclerotic lesion.

The change in cell activation is measured by factors such as the nuclear factor kappa-beta (NF-kB) detected in macrophages, vascular endothelial cells, and smooth-muscle cells of atherosclerotic lesions [7]. The proliferation of smooth-muscle cells towards the intima, associated with an increase in apoptosis and a decrease in inflammatory cells, could indicate an attempt to limit the lesion. These processes described in hyperlipaemic aortas are also found in the walls of the large choroidal vessels, where, in addition to hypertrophy of the smooth-muscle cells, a great quantity of lipid inclusions appear and, in the case of choroidal arterioles, an increase in collagen fibre of the intima and the adventitia [8].

Several mechanisms contribute to impaired vascular tone in atherosclerosis, such as the activation of the smooth-muscle cells, by e.g. the synthesis of the extracellular matrix induced by the macrophage-derived TGF-beta, the intimal thickening and the changes in the vascular endothelium, including the release of mediators that promote vascular constriction [9]. Clinical studies have suggested that hyperlipidaemia alone can prompt structural changes in the choroidal vascular and retinal system which over time could provoke retinal dysfunction [10]. Chronic ischaemia is also present in causes of blindness as prevalent as aged-related macular degeneration, glaucoma or diabetic retinopathy [11-13].

In summary, this chapter illustrates the structural and ultrastructural changes that occur experimentally in the choroids of animals subjected to a hyperlipaemic diet; the changes that appear in this tissue when the plasma-cholesterol levels are normalized after the hyperlipaemic diet is replaced by a standard one, and the effects in vascular tissue, fundamentally the mitochondria and the caveolar system of the endothelial and smooth-muscle cells, caused by the treatment with statins at such low rates that they do not alter the high cholesterol levels (pleitropic effects) but are effective for controlling chronic ischaemia.

\section{Anatomo-physiology of the choroid}

\subsection{Anatomy of the choroid}

The choroid constitutes the most posterior region of the tunica intermedia of the eyeball or uvea. This is formed by a pigmented vascular tissue underlying the sclera and overlying the retina. Histologically, the choroid has three layers, which from the sclera towards the retina are: the suprachoroid, the vascular layer, and Bruch's membrane (Figure 1A).

\subsubsection{Suprachoroid}

The suprachoroid is the outermost layer of the choroid, a transition zone between the innermost part of the sclera and the large-sized-vessel layer (Fig. 1A). It is composed of tightly packed collagen fibres, melanocytes [14], fibroblasts [15], elastic fibres [16], 
smooth-muscle cells [16-18], nerve plexus, and intrinsic choroidal neurons (ICNs) [19-21]. In primates, birds, and rabbits, this layer contains large, endothelium-lined spaces, which empty into veins.

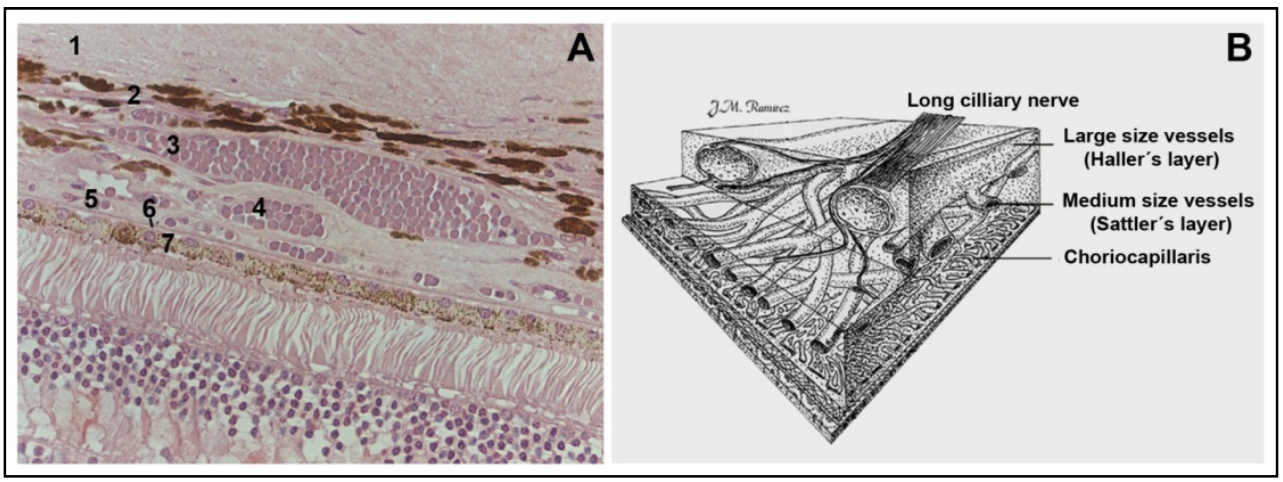

Figure 1. Choroidal vascular layers. A: Histological section (hematoxylin/eosin). B: Tridimensional scheme (Modified with permission from Ramírez et al. [19]). 1: Sclera; 2: Suprachoroid; 3: Large-sizedvessel layer (Haller's Layer); 4: Medium-sized-vessel layer (Sattler'Layer); 5: Choriocapillaris; 6: Bruch's membrane; 7: retinal pigment epithelium.

\subsubsection{Choroidal-vessel layers}

Most of the choroid consists of blood vessels that decrease in diameter from outer to inner as the vessels branch. It is made up of arteries, veins, arterioles, and a vascular stroma (Figure 1A,B). The latter contains collagen and elastic fibres, fibroblasts, non-vascular smooth cells, numerous melanocytes, mast cells, macrophages, and lymphocytes. The arterial vessels are branches of the posterior ciliary arteries (PCAs) (Figure 2) and some recurring branches of the major arterial circle of the iris [22]. The vessels become smaller in a branching hierarchy towards the capillary bed, enabling the identification of the three vessel layers of decreasing calibre [23]: an outer layer of large-sized vessels (Haller's layer), an intermediate layer of medium-sized vessels (Sattler's layer), and inner layer of interconnected capillaries (the choriocapillaris) (Figure 1A,B).

\section{Large- and medium-sized-vessel layers}

Before penetrating the sclera, the PCAs are subdivided into various branches that surround the optic disc: two long posterior ciliary arteries (LPCA) [22,24] and 15-20 short posterior ciliary arteries (SPCA) [25] (Figure 2). Depending on their scleral penetration, the SPCA can be further subdivided into paraoptic SPCA (closer to the optic disc) and distal SPCA [26,27]. Overall, 2 paraoptic SPCA pass through the sclera and surround the optic disc, thus forming the Zinn-Haller arterial circle, which provides blood flow to the circumpapillary choroid and the prelaminary and laminary regions of the optic nerve head $[27,28]$ (Figures 2,3). The rest of the SPCA, both paraoptic as well as distal, once in the vascular choroid, divide sectorially, forming triangular areas towards the 4 regions of the eyeball. The macular region is irrigated by a dense network of distal branches of the SPCA $[29,30]$. 
The LPCA penetrate the eyeball at some $4 \mathrm{~mm}$ from the optic disc in the horizontal meridians following a rectilinear path in the most superficial part of the layer of large vessels [24,27] (Figure 2). These arteries help constitute the major arterial circle of the iris $[25,31,32]$ and sends out recurrent branches toward the peripheral choroid [32,33].

As opposed to what happens throughout most of the human vascular system, the arterial and venous systems of the choroid are not parallel, as most of the veins are located primarily in the most external choroid [33]. The proportion of arteries to veins varies throughout the choroid, as does capillary density. In the latter case, density progressively diminishes from the centre to the periphery, coinciding with the fall in the number of photoreceptors of the retina. Thus, the submacular choroid is the one with the greatest capillary density (greatest quantity of blood per unit of area), this being necessary to nourish the great number of photoreceptors of the macula [23]. In this zone, the arteriole/venule ratio is 3:1, so that the foveal cones can have double their blood supply, even at the cost of greater risk of oedema by vein blockage. At the posterior pole, the arteriole:veinule ratio is 1:2 to $1: 4$ [34,35]. As a result, these zones of the choriocapillaris could be more susceptible to local blockages of arteries, with the consequent risk of ischaemic damage.

The voriticose veins drain the entire choroid, the ciliary body, and the iris. These veins are located at the equator ( 1 per each quadrant) and form a bottle shape receptacle before penetrating the sclera, which in turn is constituted by the meeting of 2 to 4 ampuliform dilations $[27,36]$. The choroidal veins and venules are larger than the arteries and maintain a rectilinear path, joining at many acute angles before ending in the vorticose veins $[15,23,33]$.

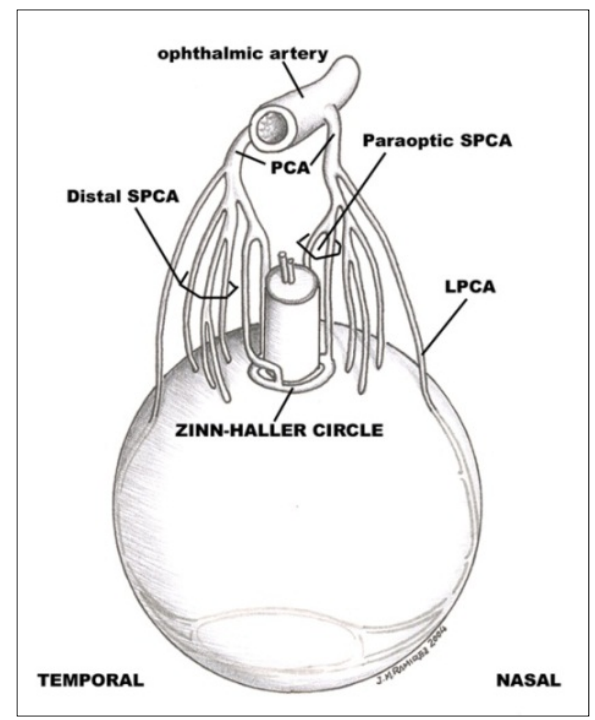

Figure 2. Scheme that represents the entry of the ciliary arteries in the eyeball. LPCA: Long posterior ciliary arteries; SPCA: Short posterior ciliary arteries; PCA: Posterior ciliary arteries. (Modified from Ramírez et al [72]). 


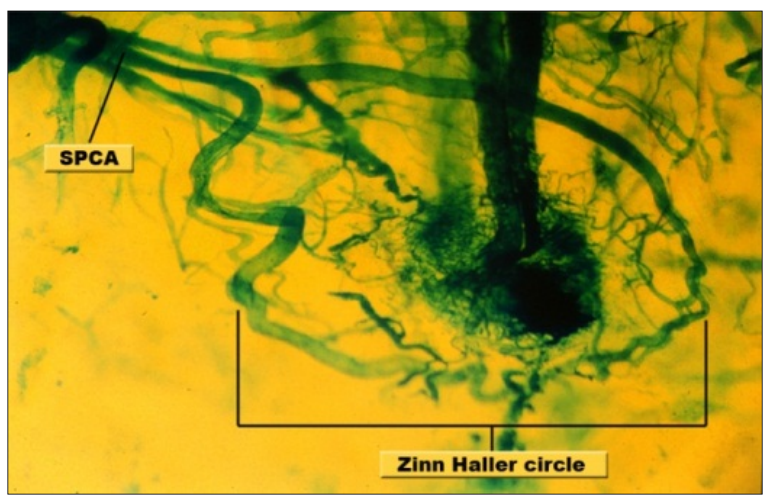

Figure 3. Diafanization and repletion with colored polymers of two short posterior ciliary arteries (SPCA) forming the Zinn-Haller arterial circle. (Modified from Ramírez et al [72]).

\section{The choriocapillaris}

The choriocapillaris is made up of capillaries situated between the medium-sized vessel layer (Sattler's layer) and Bruch's membrane (Figures 1,4). The position of these capillaries, flattened and elliptical in transverse section, create a large surface for metabolic exchange with the retina. With the same purpose, the vessels of the choriocapillaris are composed of tubes of endothelial cells (EC) and pericytes that do not completely surround it, appearing only towards the scleral side. Meanwhile, the ratio of pericytes:endothelial cells in the human retina is $1: 1$, and in the choriocapillaris it is 1:6 [23]. Given the contractile character of these cells, which enables the blood supply to be regulated in other tissues, their lower number in the choriocapillaris could suggest that the regulation of the choroidal blood flow by contraction is practically nil [23].

The EC presents fenestrations in the side oriented towards Bruch's membrane and retinal pigment epithelium (RPE) [37-39] (Figure 5). These fenestrations are of great physiological importance, as they permit the passage of nutrients towards the retina. The choroid capillaries are permeable to small molecules such as glucose (20-fold more than in cardiac muscle and 80-fold more than in skeletal muscle) [40] and amino acids [41], as well as large molecules such as $\gamma$-immunoglobulin and vitamin A [40,42,43]. Endothelial cells send out prolongations towards Bruch's membrane [44] that could physically stabilize the angioarchitecture of the inner choroid [45]. In addition, these prolongations could be involved in processes of phagocytosis for the elimination of waste products of Bruch's membrane [46], which would give them an important function in the metabolic exchange between the choroid and the RPE [47].

Among the capillaries of this layer are collagen fibres that form intercapillary septa [48]. These septa are reinforced and intermixed with fibres that come from the collagen area of Bruch's membrane [23]. In this way, the capillaries are immersed in a network of relatively rigid collagen that prevents collapse [15]. 


\subsubsection{Bruch's membrane}

The innermost layer of the choroid is Bruch's membrane. This is an acellular structure, easily distinguishable from the retina and the choroid, and contains elements of both tissues. According to studies made with the electron microscope [15] [49][49][49] it can be divided into five layers, which, from the choroid side towards the retina are: The basal membrane of the choriocapillaris, the outer collagen layer, the elastic-fibre layer, the inner collagen layer, and the basal membrane of the RPE (Figure 5).

The basal membranes, which on one side separate Bruch's membrane from the choriocapillaris, and on the other from the RPE, are not joined by the hemidesmosomes to their adjacent layers [50]. The basal membrane of the choriocapillaris is discontinuous [15], being present on the side of the endothelium of the capillaries but absent in the intercapillary spaces [50].

The two collagen layers, with a thickness of $1 \mu \mathrm{m}$ in young individuals, surround the layer of elastic fibres [15]. Some collagen fibres are arranged parallel to the plane of the tissue, particularly at the level of the inner collagen. Others pass from one side to the other of the elastic-fibre layer, interconnecting both collagen layers [15,33]. Through the external collagen, fibres penetrate the interruptions of the basal membrane to join the collagen fibres of the intercapillary septa (as described above). This arrangement can help to join Bruch's membrane to the choriocapillaris.

The elastic fibre layer lies between the inner collagen layer on the inside and the outer collagen layer on the outside. It is made-up of inter-woven bands of elastic fibres 2-4 $\mu \mathrm{m}$ thick. Between these appear irregular spaces through which the collagen fibres pass [15].

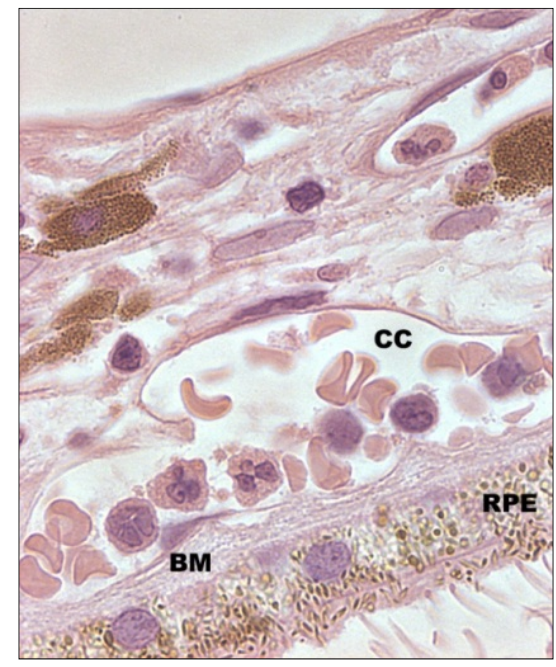

Figure 4. Histologic section of the choriocapillaris (CC), Bruch's membrane (BM) and retinal pigment epithelium (RPE). Hematoxylin/eosin. (Modified from Ramírez et al [72]). 


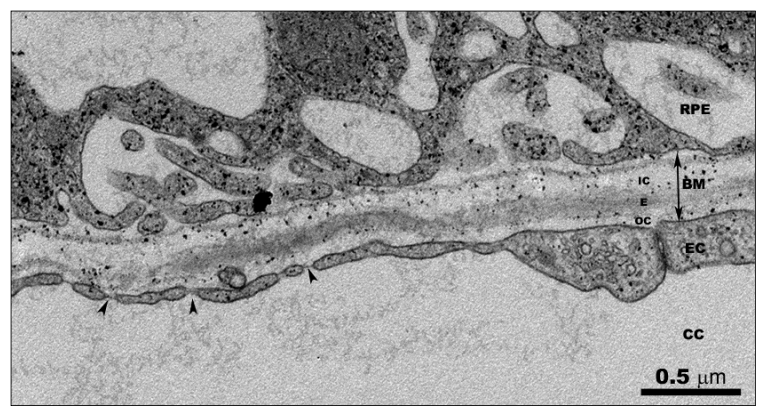

Figure 5. Electron micrograph of Bruch's membrane (BM) and choriocapillaris (CC). Bruch's membrane is composed of several layers: the basal membrane of the retinal pigment epithelium (RPE), the inner collagenous layer (IC), the elastic layer (E), the outer collagenous layer (OC) and the basal membrane of the choriocapillary endothelium. Endothelial cells (EC) of the choriocapillaris present fenestrations (arrow-head).

\subsubsection{Choroidal innervation.}

The abundant choroidal innervation is made up of fibre bundles from the sympathetic and parasympathetic (autonomic nervous system) and sensitive (central nervous system). The sympathetic fibres are from the superior cervical ganglion, the parasympathetic from the ciliary and pterygopalatine ganglion, and the sensitive fibres from the trigeminal ganglion. These nerve fibres reach the choroid in three ways: i) going around the SPCA, these fibres stem from the plexuses of the internal carotid and continue with the ophthalmic artery until reaching the SPCA in the choroid; ii) through the short posterior ciliary nerves that stem from the ciliary ganglion; or iii) through the long posterior ciliary nerves that come from the nasociliary nerve $[19,20]$ (Figure 6). In addition to the nerve fibres, the choroid has intrinsic choroidal neurons (ICNs). Both nervous structures are more abundant in the suprachoroid than in the rest of the vascular layers, with no innervation in the choriocapillaris [20].

\section{Nerve Fibres}

The long ciliary nerves (nasal and temporal) enter the choroid together with the LPCA, in the horizontal meridian of the eye, near the optic disc. They head towards the anterior part of the eyeball, with few branches in the part towards the suprachoroid or the choroidal vessel layers [20] (Figure 6). The short ciliary nerves enter the choroid together with the SPCA around the optic nerve and proceed towards the ciliary body. In this trajectory, there are many branches for the suprachoroid and the choroidal vessel layers [20] (Figure 6).

The short and long ciliary nerves send out branches to the large-sized-vessel layer of the choroid that are arranged in a paravascular form (Figure 7). Immunohistochemical techniques have demonstrated that these paravascular axons carry information which is sympathetic $[\mathrm{NPY}(+)$ and $\mathrm{TH}(+)][21]$; parasympathetic $[(\mathrm{VIP}(+)]$, and sensitive $[\mathrm{SP}(+)$ and CGRP $(+)$ ] [51]. In addition, in the vascular walls, sympathetic perivascular ends [NPY $(+)$ and $\mathrm{TH}(+)]$ as well as sensitive ones $[\mathrm{SP}(+)$ and $\mathrm{CGRP}(+)]$ have been described. These perivascu- 
lar fibres can present small end dilations on reaching the vascular wall. Some axons penetrate to a deeper level of the medium-sized-vessel layer to form a polygonal plexus. This axons are sympathetic $[\mathrm{NPY}(+)$ and $\mathrm{TH}(+)]$ and sensitive $[\mathrm{SP}(+)$ and $\mathrm{CGRP}(+)]$. Innervation has not been demonstrated in the choriocapillaris [21,51,52].

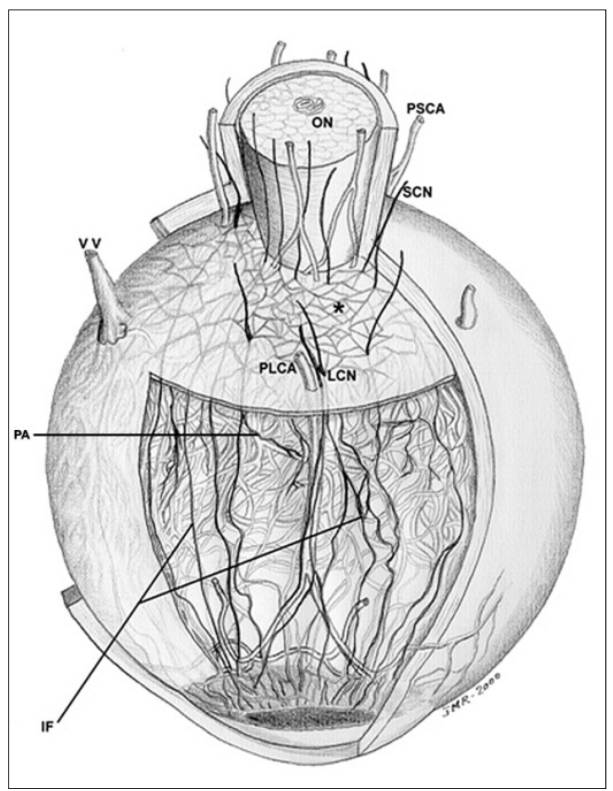

Figure 6. Tridimensional scheme showing the topographic distribution of the short ciliary nerves (SCN) and long ciliary nerves ( $\mathrm{LCN}$ ) in human choroid. The short ciliary nerves form a plexus of nerve fibers in the suprachoroid. In the vascular layers, the scheme shows branches from this plexus adapting to the vessel contours - paravascular fibers (PF) and intervascular fibers (IF). ON: optic nerve; PSCA: short posterior ciliary arteries; PLCA: Long posterior ciliary arteries; VV: vorticose vein; asterisk: posterior pole. (From Triviño et al. [20]

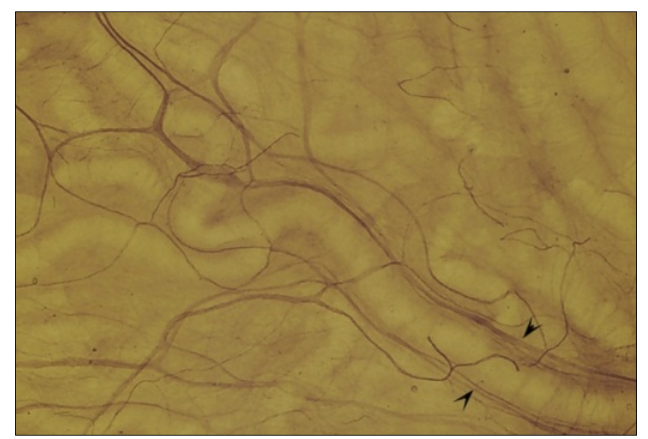

Figure 7. Human choroidal wholemount. Nerve fibers adapted to the choroidal vascular morphology (paravascular fibers) lying parallel to the large arteries (arrow-head). Anti NF-200 PAP. Bar: $250 \mu \mathrm{m}$. (From Triviño et al. [20]) 


\section{Intrinsic choroidal neurons (ICNs)}

Besides nerve fibres, the human choroid possesses abundant ICNs (from 1300 to 1500), which are located mainly in the suprachoroid (Figure 8). The greatest concentration of ICNs is found in the central and temporal region adjacent to the macula. This location could be related to the existence of the macula. In humans, ICNs could be responsible for regulating the rapid vasoregulatory reflexes, which are so important in the fovea [20].

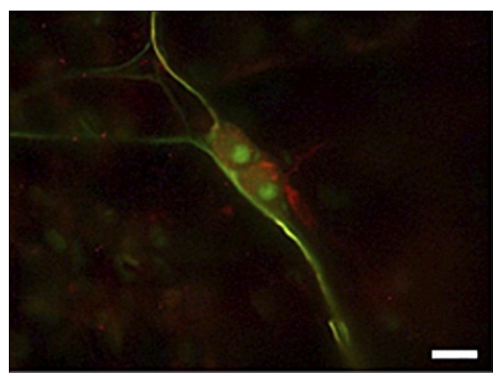

Figure 8. Intrinsic choroidal neurons of the suprachoroid forming a microganglion. Double immunofluorescence for NF 200 (green) and TH (red). Bar: $20 \mu \mathrm{m}$. (From Triviño et al. [21])

The ICNs can present immunoreactivity to VIP (parasympathetic) and to nitric oxide synthase (NOS), indicating the use of nitric oxide (NO) as a neurotransmitter. Both the NO and the VIP would be involved in the vasodilation through the regulation of the vascular smooth-muscle fibre. Recently, ICNS have been reported to be immunoreactive to NPY and TH (sympathetic) (Figure 8) and to SP and CGRP (sensitive) [52]. All these are located preferentially in the central region of the temporal area (submacular choroid). Sympathetic ICNs could exert a protective mechanism to prevent over-perfusion and breakdown of barriers [21]. Sensitive ICNs could be involved in regulating the ocular blood supply, inflammatory processes, and vascular architecture [52].

\subsubsection{Ultrastructural anatomy}

\section{Choroidal arteries and veins}

The choroidal arteries have the structure of small arteries. They are constituted by a tunica intima, which consists of a monolayer of EC, a basal membrane often containing a cluster of fine osmophilic particles and of interspersed elastic fibres [15]. The intima is surrounded by a thick tunica media made up by one or more layers of smooth-muscle cells (Figure 12A). In larger arteries, there are two to three layers of smooth-muscle cells, the innermost arranged circumferentially and the outermost obliquely or longitudinally. These cells are separated from each other by basal membranes [53]. Over the tunica media lies an adventitia of collagen in a circular arrangement but without an outer elastic membrane. In the adventitia, there are often melanocytes and fibroblasts [54]. The choroidal arterioles are constituted by: an intima, formed only by an endothelium and a basal membrane without inner elastic; a tunica media made up of a discontinuous muscle layer; and an adventitia formed by a fine layer of circular collagen [15]. 
Choroidal veins have a structure similar to the rest of the veins of the organism, are composed of an endothelia, a basal membrane, one or two layers of muscle cells, and an adventitious layer of collagen [23]. Clusters of unmyelinated axons and synaptic terminals reach the outer muscle layers of the veins and arteries. Terminal boutons make contact with the smooth-muscle cells [53].

The EC, both of the arteries as well as of the choroid veins, present evaginations that protrude towards the inside of the vessel and towards the basal membrane. These later pass through the membrane and make contact with the closest muscle cells. In the cytoplasm of the EC the normal organelles can be found: mitochondria, Golgi apparatus, rough endoplasmic reticulum, caveolar system, free polyribosomes, cytoplasmic vesicles and WeibelPalade bodies, which are membrane-bound granules containing an electrodense material $[54,55]$. The processes of the EC overlap and are joined together by different types of cell bonds: zonula adherens, tight junctions, and long gap junctions [38] (Figure 13A).

The vascular smooth-muscle cells (VSMC) contain an elongated, highly heterochromatic nucleus, a cytoplasm with elongated mitochondria having smooth and rough-surfaces, endoplasmic reticulum, and numerous contractile filaments oriented parallel to one other [54]. Among the bundles of filaments appear dense osmiophilic structures that resemble $\mathrm{Z}$ bands, which probably represent areas of attachment of the filaments. Other filaments are oriented towards thickenings of the cell membrane; the filaments join these thickenings in the same way as hemidesmosomes [15]. Alternating with the dense structures, rows of caveoles appear along the surface of the cell membrane [55]. The muscle cells are joined together by macular adherent junctions, punctiform junctions, and gap junctions [54] (Figure 13A).

\section{Choriocapillaris}

The capillaries of the choriocapillaris differ from those of the retina by the great diameter of its lumen, in such a way that red blood cells can pass through at least 2 or 3 at a time [23].The EC of these capillaries have their nuclei located on the side of the vessels opposite Bruch's membrane and protrude slightly into the lumen. Its cytoplasm, contains scattered mitochondria, small portions of Golgi apparatus, short cisterns of rough endoplasmic reticulum, free polyribosomes, cytoplasmic vesicles, caveolar system, and occasional WeibelPalade bodies [54].

The EC are joined together by thin discontinuous bonds (zonula occludens), desmosomes, and communicating junctions (gaps) $[37,38,56]$. In addition, they have the peculiarity of presenting fenestrations on the side oriented towards Bruch's membrane and the RPE [3739]. These fenestrations have a mean pore size of $60-80 \mathrm{~nm}[15,23]$ and are crossed by a diaphragm with a central density [37] (Figure 5). Endothelial-cell processes protrude into Bruch's membrane, typically at sites of focally thickened, nonfenestrated regions of the EC [46]. The endothelium is enveloped by a thin basal lamina which also surrounds the pericytes $[14,57,58]$. Pericytes appear only on the scleral face of the capillaries, incompletely wrapping them [23]. In their cytoplasm, pericytes bear small bundles of microfilaments, preferentially located along the plasma membrane [54,59]. 
The stroma (extravascular tissue) contains collagen and elastic fibres, fibroblasts, nonvascular smooth-muscle cells and numerous very large melanocytes closely apposed to the blood vessels. As in other types of connective tissue, numerous mast cells, macrophages and lymphocytes appear ([60] (Figures 11A,12A).

\subsection{Choroidal physiology}

The choroid is one of the most vascularized tissues of the human body and therefore it has traditionally been thought that its main function was to nourish the external layers of the retina. However, today it is known that it has many other functions, including: light absorption, elimination of the aqueous humour from the unveoscleral pathway, adjustment of the position of the retina by changes in the choroid thickness, help in the control intraocular pressure, and thermoregulation. The latter two functions of the choroidal blood flow have a fundamental role.

\subsubsection{The role of the choroidal blood flow}

The choroidal blood flow represents some $85 \%$ the total blood in the eye [34]. This high flow rate considerably surpasses that of other richly vascularized tissues, being 10-fold higher than in the grey matter of the brain, and 4-fold that of the kidney. This high choroidal bloodflow rate $(800-2000 \mathrm{ml} / \mathrm{min} / 100 \mathrm{gr}$ of tissue) is probably due to the great calibre of the vascular lumen of the choriocapillaris, and therefore to its low flow resistance [24,61]. Furthermore, the blood flow is not uniform, as it presents regional differences throughout the choroid, so that on the periphery the flow is 6- to 7-fold lower than in the central regions (foveal and peripapillary) [62].

The exact function of the high choroidal blood flow is still not known with exactitude. Physiologically, one of the main functions of the choroid is to nourish (supply $\mathrm{O}_{2}$ and glucose) to the most external layers of the retina (fundamentally to the photoreceptors and to the RPE). In many species, the retina depends entirely on choroidal circulation for its metabolic needs. The human choroid provides the metabolic requirements to the entire thickness of the retina only in the macular region. The high choroidal blood flow results in a steep gradient for the diffusion of $\mathrm{O}_{2}$ towards the external layers of the retina and a low concentration of waste products, facilitating their elimination from the retina [1]. If we take into account that vein blood is approximately $95 \%$ of that found in the arterial blood, we see that the $\mathrm{O}_{2}$-extraction rate from choroidal arterial blood is only 3-5\% [63]. However, the high blood flow through its vessels permit the choroid to provide a high percentage of oxygen consumed by the retina.

Nevertheless, the choroid appears to be perfused at a proportion that exceeds its nutritive needs, suggesting therefore an additional role for the high rate of choroidal flow. Thus, it is thought that the choroidal blood flow could help maintain the regulation of the intraocular pressure (IOP) [43] and, on the other hand, offer thermoregulation by the following mechanisms: dissipating the heat generated during the visual transduction process [64], preventing overheating of the outer retina during exposure to bright light [65], and, finally, heating 
the intraocular structures that could be cooled by exposure to extreme outside conditions [66].

\subsubsection{Regulatory mechanisms of choroidal blood-flow}

The control of circulation in most tissue is quite complex, as there are many factors that influence vascular resistance, such as: local myogenic responses, substances derived from the endothelium, local metabolic factors, and the autonomous nervous system. The existence or not of choroidal self-regulating mechanisms has long been the object of debate. The pressure that promotes blood flow through the tissues is called perfusion pressure. Ocular perfusion pressure is the difference between the pressure of the arteries that reach the eye $(\mathrm{aP})$ and that of the veins that leave the eye $(\mathrm{vP})$ [1]. The perfusion pressure and vascular resistance $(\mathrm{R})$ determine blood flow $(\mathrm{F})$ according to the following formula: $\mathrm{F}=(\mathrm{aP}-\mathrm{vP}) / \mathrm{R}$. As in the eye, the vP is practically equal to the IOP both under normal conditions as well as in cases of increased IOP, so that the formula becomes: $\mathrm{F}=(\mathrm{aP}-\mathrm{IOP}) / \mathrm{R}$. According to this formula, a decrease in the perfusion pressure (by relieved arterial pressure or greater IOP) could result in a proportional restriction of blood flow without a compensatory reduction in vascular resistance [33].

In most tissues, blood flow tends to remain constant despite moderate variations in perfusion pressure, thanks to the mechanism known as self-regulation [24]. However, in the choroid, as opposed to the retinal vessels and the prelaminary region of the optic disc, increases (even moderate ones) in the IOP, cause concomitant reductions of the choroidal blood flow [63]. This circumstance is not controlled by any self-regulated mechanism $[67,68]$. Nevertheless, some authors have considered there to be a certain self-regulatory capacity of choroidal circulation under very specific conditions. Thus, it has been demonstrated that the choroidal circulation is sensitive to tensions of $\mathrm{CO}_{2}$ as well as to acidic metabolic products which cause vasodilation. Studies on cats have shown a marked vasodilation in the choroid when the $\mathrm{CO}_{2}$ concentration is raised [69]. It has been observed that the flow augments with the respiration of air containing $10 \% \mathrm{CO}_{2}$ and diminishes with respiration of air saturated with $100 \% \mathrm{O}_{2}$ [70]. Other studies reveal evidence of choroidal self-regulation when the average arterial pressure gradually weakens. This mechanism is IOP dependent, so that its effect is far more pronounced at low IOP levels $(<5$ $\mathrm{mmHg}$ ) and does not occur within normal or higher IOP ranges. Therefore, the choroid would be capable of regulating its circulation at extremely low perfusion pressures induced by a fall in average arterial pressure.

Neural control of choroidal blood-flow

In recent years, the importance of the neural control in choroidal blood-flow regulation has been stressed. Several mechanisms are involved in the neuroregulation of the uveal flow. In a direct way, this flow is regulated by perivascular innervation, which permits a balance between the vasoconstriction and vasodilation necessary for the maintenance of blood flow. Indirect regulation comes from the paravascular fibres, both by means of classical neurotransmitters as well as neuropeptides released by sympathetic, parasympathetic, and stroma-sensitive nerve endings, and diffusing factors such as NO [20]. 
Sympathetic stimulation causes sharp choroidal vasoconstriction and a fall in intraocular pressure due to a decline in the ocular blood volume (reductions in choroidal flow of up to $60 \%$ ) [62]. This response comes fundamentally from the stimulation of $\alpha$-adrenergic receptors located in the VSMC [1]. The sympathetic innervation places the choroid under vasoconstriction tone, suggesting that this could protect the retina and the optic nerve head from the hyperfusion and break of the ocular barriers that could appear under certain circumstances as for example arterial hypertension. The systemic hypotension would, by barroreflex, increase sympathetic activity and depress parasympathetic activity, which would in turn bolster vascular resistance in the choroid, with the consequent restriction in choroidal blood flow. This situation has not been confirmed in experimental studies [71], indicating that there could be a local mechanism in the choroid capable of ignoring neurogenic vasoconstriction, or the choroidal nerves do not become activated during the discharge of the barroreceptors. Other authors [62,63] have demonstrated that, although during the direct stimulation of the sympathetic activity, it has little effect on the diminished choroidal flow during the hypotension induced by a haemorrhage. The existence of sympathetic neurons in the choroid (ICNs) immunopositive for NPY and TH [21], could partly explain the selfregulatory capacity of the choroid.

The role of the parasympathetic innervation it is not as clearly defined as the sympathetic one. However, it has been observed that the choroid responds to cholinergic parasympathetic stimulation (which arrives through the short ciliary nerves) by vasodilation. This vasodilation would explain the increase light-induced choroidal blood flow [72].

Recently, it has been postulated that the sensitive peripheral nerves play an important role in choroidal blood-flow regulation. Thus, SP could have a viscero-motor function, regulating the choroidal flow during ocular irritation. In addition, a role in vasodilation has been attributed to the CGRP as a cholinergic co-mediator with the SP [52].

\section{Neural control of choroidal blood flow in ocular diseases}

The importance exerted by nerve control on the regulation of choroidal blood flow appears to imply that damage in the choroidal innervation could be involved in the vascular alterations that occur in some ocular diseases. Experimental studies have demonstrated that sympathetic innervation is critical in the regulation of choroidal vascularization [73], and that the chronic loss of sympathetic activity can contribute to the anomalous vascular proliferation noted in diseases such as age-related macular degeneration (ARMD) [74] and diabetic retinopathy $[75,76]$. Furthermore, the loss of this innervation can cause oedema in the retina [71], a circumstance that could be important in illnesses such as diabetes or hypertension, in which automatic control is altered [56].

The axonal damage in the sympathetic nervous system is a notable fact of diabetic neuropathy. In addition, a dysfunction of the sympathetic nerves of the eye in diabetic patients has been suggested, postulating that the episodes of hyperglucaemia could determine an increase in the choroidal flow and in the pressure of the vessels in the submacular choroid, as well as changes in the RPE. In this way, the extravasation of fluid from the submacular choroid would be exacerbated. The excess of intraretinal liquid caused 
by diabetic macular oedema would not come from the retinal vessels alone but also from the choroid, reaching the retina through lesions of the RPE near the choriocapillaris affected [77].

In ARMD, haemodynamic anomalies have been reported as potential causal agents as part of the pathological process. By laser Doppler flowmetry, it has been observed that the choroidal blood flow diminishes with age [78], and it is lower in the non-exudative stages of macular degeneration than in control. This effect is due to a descent in the volume of blood flow [79].

Recently, it has been postulated that the sensitive nerves could be involved in regulating choroidal flow through different inflammatory mechanisms that measure vasodilation and plasma extravasation. Also, its role has been examined in processes of maintenance and vascular renovation with substantial implications in visual function [23]. Thus, it has been suggested that changes in choroidal thickness would play a main role in the regulation of this ocular refractive state, particularly in recuperation from myopia [22]. Additionally, the diabetes-like conditions induced by streptozotocin reduce the content of CGRP in the sensory nerves and exogenous CGRP-mediated vasodilation. CGRP is likely an important regulator of vascular tone, and compromising its function could contribute to nerve ischaemia and diabetic neuropathy [80]. It has been postulated that the dysfunction of $\mathrm{SP}(+)$ and/or CGRP(+) ICNs could be involved in the physiopathology of ocular diseases associated with peripheral innervation damage. The majority distribution of sympathetic and sensitive ICNs in the submacular region suggests the possibility that vascular pathologies of certain ocular diseases such diabetic macular oedema or agerelated macular degeneration are related to the possible dysfunction of these cells $[20,21,52]$.

It appears that the peripheral innervation, both sensitive as well as sympathetic, would have a broad and significant role in regulating the choroidal vascular architecture. Moreover, given the special susceptibility to damage presented by peripheral innervation under a great variety of conditions (age, arterial hypertension, ocular hypertension, diabetes), sympathetic and sensitive choroidal nerve dysfunction could intervene in the aetiology of ocular diseases that appear in association with these conditions [21,52].

\section{Hypercholesterolaemia as a risk factor for smooth-muscle and endothelial cell dysfunction}

Atherosclerosis results from a local imbalance between the production of reactive oxygen species (ROS) and antioxidant enzymes. The EC, macrophages, and VSMC are targets for ROS-dependent atherogenic signalling [81]. Our data suggest that changes in arterial ROS production may occur very early in hypercholesterolaemia. Atherosclerosis is initiated by lipids deposited in the subendothelial layer of the artery wall. These lipids and modified LDL, oxidized low-density lipoprotein (Ox-LDL), induce the expression of adhesion molecules and chemotactic molecules including monocyte chemoattractant protein-1 (MCP- 
1/CCL2). After activating EC in this way, monocytes/ macrophages enter the intima and differentiate [82]. Lipid-laden macrophages, known as foam cells, promote the progression of the atherosclerotic plaque [83]. Specifically, pro-inflammatory cytokines and growth factors secreted by foam cells induce local inflammatory responses, ROS in the lesion, and accelerate the migration of VSMC from the media to the intima [84]. Intimal VSMC also take up modified lipoproteins, contributing to foam-cell formation, and synthesise extracellular matrix proteins (collagen, elastin, and proteoglycans) that lead to the development of a fibrous cap [85].

In VSMC, ROS mediates various functions, including growth, migration, matrix regulation, inflammation, and contraction [86], which are critical factors in the progression and complication of atherosclerosis. VSMC regulate plaque stability by modulating inflammation and apoptosis and by producing or degrading matrix proteins [85,87]. Under atherogenic conditions, VSMC in the media of the artery undergo phenotypic changes from the normal contractile state to the active synthetic state, which produces collagen, elastin, and proteoglycans. Activated VSMC migrate to the intima and proliferate [88]. In addition, ROS produced via NADPH oxidase induce VSMC to produce and secrete matrix metalloproteinases involved in the degradation and reorganization of the extracellular matrix [89]. In VSMC, ROS also mediate inflammation (e.g., MCP-1 expression via TNF- $\alpha$ ) [90] and apoptosis via p53 and Bax/Bad [91].

The junction integrity of EC in blood vessels regulates leukocyte transmigration. In this process, ICAM-1 and VCAM-1 clustering prompts actin remodelling and junction disruption via ROS production [82].

It has been reported that Ox-LDL affects endothelium-dependent responses [92]. Some studies demonstrate that Ox-LDL decreases the endothelial release of NO [93] and that endothelium-dependent relaxations are improved by lipid-lowering therapy in patients with hypercholesterolaemia [94]. Another study suggests a mechanism for the cholesterol-induced impairment of NO production through endothelial nitric oxide synthase (eNOS) regulation by inhibitory interaction with caveolin [95].

\section{Animal models of hypercholesterolaemia}

Animal models provide a controlled environment in which to study disease mechanisms and to devise technologies for diagnosis and therapeutic intervention for human atherosclerosis. Different species have been used for experimental purposes (cat, pig, dog, rabbit, rat, mouse, zebra fish). The larger animal models more closely resemble human situations of atherosclerosis and transplant atherosclerosis and can also be easily used in (molecular) imaging studies of cardiovascular disease, in which disease development and efficacy of (novel) therapies can be monitored objectively and non-invasively. Imaging might also enable early disease diagnosis or prognosis [96]. On the other hand, the benefits of genetically modified inbred mice remain useful, especially in quantitative trait locus (QTL)-analysis studies (a genetic approach to examine correlations between genotypes and phenotypes and to identify (new) genes underlying polygenic traits [96]. 


\subsection{Mice}

Wild-type mice are quite resistant to atherosclerosis as a result of high levels of antiatherosclerotic HDL and low levels of pro-atherogenic LDL and very-low-densitylipoproteins (VLDL). All of the current mouse models of atherosclerosis are therefore based on perturbations of lipoprotein metabolism through dietary or genetic manipulations [97].

\section{ApoE-knockout mice}

In apoliprotein-deficient mice (apoE $\mathrm{E}^{-/}$) the homozygous delection of the apoE gene results in a pronounced rise in the plasma levels of LDL and VLDL attributable to the failure of LDLreceptor (LDLr-) and LDL-related proteins (LRP-) mediated clearance of these lipoproteins. As a consequence, apoE $\mathrm{E}^{-/-}$mice develop spontaneous atherosclerosis. Of the genetically engineered models, the apoE-deficient model is the only one that develops extensive atherosclerotic lesions on a low-fat cholesterol-free chow diet $(<40 \mathrm{~g} / \mathrm{kg})$. The development of atherosclerosis lesion can be strongly accelerated by a high-fat, high-cholesterol (HFC) diet [98]. ApoE-knockout mice have played a pivotal role in understanding the inflammatory background of atherosclerosis, a disease previously thought to be mainly degenerative. The apoE-deficient mouse model of atherosclerosis can be used to: i) identify atherosclerosissusceptibility-modifying genes; ii) define the role of various cell types in atherogenesis; iii) characterize environmental factors affecting atherogenesis; and iv) to assess therapies [99]. Because of the rapid development of atherosclerosis and the resemblance of lesion to human counterparts, the apoE ${ }^{-/}$model have been widely used. However, some drawbacks are associated with the complete absence of apoE proteins: i) the model is dominated by high levels of plasma cholesterol; ii) most plasma levels are confined to VLDL and not to LDL particles, as in humans; and iii) apoE protein has additional antiatherogenic properties besides regulating the clearance of lipoproteins such as antioxidant, antiproliferative (smooth-muscle cells, lymphocytes), anti-inflammatory, antiplatelet, and also has NO-generating properties or immunomodulatory effects [100-102]. The study of the above processes and the effects of drugs thereupon is restricted in this model.

\section{LDLreceptor-deficient mice (LDLr-- mice)}

In humans, mutations in the gen for the LDLr cause familial hypercholesterolaemia. Mice lacking the gene for LDL receptor (LDLr ${ }^{--}$mice), develops atherosclerosis, especially when fed a lipid-rich diet [103]. The morphology of the lesions in $\mathrm{LDLr}^{-/}$mice is comparable to that in apoE-/, while the main plasma lipoprotein in $\mathrm{LDLr}^{-/}$mice are LDL and high-densitylipoprotein (HDL) [104].

\section{ApoE*3Leiden (E3L) transgenic mouse}

ApoE*3Leiden (E3L) transgenic mice are being generated by introducing a human ApoE*3Leiden construct into C57B1/6 mice. E3L mice develop atherosclerosis on being fed cholesterol. Because they are highly responsive to diets containing fat, sugar, and cholesterol, plasma lipid levels can easily be adjusted to a desired concentration by titrating the amount of cholesterol and sugar in the diet. E3L mice have a hyperlipidaemic phenotype with a prominent 
increase in VLDL- and LDL-sized lipoproteins fractions [105] and are more sensitive to lipid-lowering drugs than are apoE $\mathrm{E}^{-/-}$and $\mathrm{LDLr}^{-/-}$mice [97].

\subsection{Minipigs}

Because of their well-known physiological and anatomical similarities to humans, swine are considered to be increasingly attractive toxicological and pharmacological models. Pigs develop plasma cholesterol levels and atherosclerotic lesions similar to those of humans, but their maintenance is more difficult and expensive than that of smaller animals [96]. The minipig, smaller than the domestic swine, has served as a model of hypercholesterolaemia for more than two decades now. In 1986, Jacobsson reported that the Göttingen strain had more susceptibility to alimentary hypercholesterolaemia and experimental atherosclerosis than did domestic swine of the Swedish Landrace [106]. Clawn[107], Yucatan, Sinclair, and Handford are among other general minipigs used for experimental use [107-109]. Downsized Rapacz pigs are minipigs with familial hypercholesterolaemia caused by a mutation in the low-density lipoprotein receptor. It is a model of advanced atherosclerosis with human like vulnerable plaque morphology that has been used to test an imaging modality aimed at vulnerable plaque detection [110]. The Microminipig (MMP) is the smallest of the minipigs used for experimental atherosclerosis [111]. One of its advantages is that in 3 months an atherosclerosis very similar in location, pathophysiology and pathology to that in humans can be induced [112]. The easy handling and mild character of the MMP make it possible to draw blood and conduct CT scanning under non-anaesthesized conditions [113].

\subsection{Zebra fish}

Cholesterol-fed zebra fish represent a novel animal model in which to study the early events involved in vascular lipid accumulation and lipoprotein oxidation $[114,115]$. Feeding zebra fish a high-cholesterol diet results in hypercholesterolaemia, vascular lipid accumulation, myeloid cell recruitment, and other pathological processes characteristic of early atherogenesis in mammals [113]. The advantages of the zebra-fish model include the optical transparency of the larvae, which enables imaging studies.

\subsection{Rabbits}

Investigation has continued on hypercholesterolaemic rabbits since 1913, when Anitschkow demonstrated that, in rabbits fed a hypercholesterolaemic diet underwent atherosclerotic changes at the level of the arterial intima similar to those in atherosclerotic humans. The atheromatose lesions in this animal are similar to those in humans also in sequence, as confirmed en aortic atherosclerosis [116], making this animal a universal model for studying the anti-atherogenic activity of many drugs [117-120]. For the characteristics detailed below, the New Zealand rabbit is an excellent model to reproduce human atheromatosis because: i) it is possible to induce hypercholesterolaemia in a few days after administration of a highcholesterol diet [121]; ii) it is sensitive to the induction of atheromatose lesions [116]; iii) 
hypercholesterolaemia results from excess LDL [122]; iv) excess cholesterol is eliminated from the tissues to be incorporated in high-density lipoproteins (HDL) [4]; vi) it is capable of forming cholesterol-HDL complexes associated with apoE which are transported by the blood to the liver [4]; vii) the lipoprotein profile is similar in size to that of humans in the highest range, with HDl being practically the same [123]; viii) it presents postprandial hyperlipaemia for the existence of chilomicron remnants [124]; ix) the hyperlipaemic diet increases apoE [125]; and $x$ ) the sustained alteration of lipids after feeding with a cholesterolrich diet is reversible when the diet is replaced by a normal one [121].

Studies on hypercholesterolaemic rabbits have improved our knowledge of human atherosclerosis by delving into different aspects of the disease such as lipoproteins, mitogenes, growth factors, adhesion molecules, endothelial function, and different types of receptors. At the vascular level, the importance of endothelial integrity and cell adhesion has been investigated [126]. It has been demonstrated that the high levels of lysosomal iron start the oxidation of the LDL, spurring the formation of lesions [127]. In addition, the expression of VCAM-1 preceding the infiltration of the subendothelial space by macrophages has been studied [128], as have the proteins, including MCP-1. In hypercholesterolaemic rabbits, this protein is over-expressed when the serum-cholesterol levels rise in macrophages and smooth-muscle cells, contributing to the development of fatty streaks [2].

In hypercholesterolaemic rabbits, the expression de Fas-L in cells of the arterial wall help us to understand the progression of the atherosclerotic lesion, as this expression indicates an increase in cell injury, as well as a greater accumulation in the intima of smooth-muscle cells [8]. Also, a hyperlipaemic diet causes a selective alteration of the functioning of certain regulatory proteins that are involved in gene expression, as occurs with the nuclear B factor, which stimulates the proliferation of macrophages and smooth-muscle cells [129].

In this model, a study was also made of the pre-thrombosis state triggered by the platelet aggregation in an altered endothelium and the possibilities of its inhibition [130], as well as the interactions of the LDL with the extracellular matrix to form aggregates that accumulate in the intima of the artery wall [9].

The consequences of hypercholesterolaemia in ischaemic cardiopathy and cerebrovascular pathology are well known. The same does not occur with the functional repercussions of the hypercholesterolaemia at the ocular level, partly because the underlying structural changes are not well known. The hypercholesterolaemic rabbit constitutes a useful model to explore the repercussions of excess lipids at the ocular level. This is because rabbits are susceptible to both systemic as well as the ocular alterations. One of the broadest contributions made to the implications of experimental hypercholesterolaemia at the ocular level was that of Françoise and Neetens [131]. These authors, apart from analysing the changes in the liver, spleen, adrenaline glands, heart, aorta, and supra-aortic trunk, described the most significant ocular findings, such as the accumulation of lipids in the choroid, retinal disorganization, and lipid keratopathy. With respect to the retinal macroglia, the synthesis of the ApoE by the Müller cells, its subsequent secretion in vitro, and its being taken up by the axons and 
transported by the optic nerve enabled the detection of ApoE in the latter geniculate body and in the superior colliculus [132].

Studies with electron microscopy on hypercholesterolaemic rabbits have revealed hypercellularity and optically empty spaces in the corneal stroma. These optically empty spaces, with an elongated or needle shape, were previously occupied by crystals of cholesterol monohydrate or crystals of cholesterol esters [133]. In other studies, the analysis in the form adopted for the crystallizations of the different types of lipids revealed that the needles corresponded to esterified cholesterol, and the short, thin ones to triglycerides [4]. Both crystallizations appear to be associated with other components such as collagen.

In addition, the formation of foam cells as a consequence of phagocytes from the macrophage-oxidized LDL has also been detected, with the retention of cholesterol in the vascular wall and the activation of ACAT (acetyl-cholesterol-acyl-transferase) [5], this point being key to the role of macrophages in the progression or regression of the lesions [4].

\section{Watanabe}

The Watanabe heritable hyperlipidaemic (WHHL) rabbit is an animal model for hypercholesterolaemia due to genetic defects in LDL receptors [134] and a lipoprotein metabolism very similar to that of humans [135]. These features make WHHL rabbits a true model of human familial hypercholesterolaemia. The first paper on the WHHL rabbit was published in 1980 [136]. The original WHHL rabbits had a very low incidence of coronary atherosclerosis and did not develop myocardial infarction. Several years of selective breeding led to the development of coronary atherosclerosis-prone WHHL rabbits, which showed metabolic syndrome-like features, and myocardial infarction-prone WHHLMI rabbits. WHHL rabbits have been used in studies of several compounds with hypocholesterolaemic and/or antiatherosclerotic effects with special relevance for statins [135]. Recently, WHHLMI rabbits have been used in studies of the imaging of atherosclerotic lesions by MRI [137], PET [138] and intravascular ultrasound [139].

\section{Statins}

Hypercholesterolaemia is a known risk factor for cardiovascular disease, and statin therapy has led to a significant reduction in morbidity and mortality from adverse cardiac events, stroke, and peripheral arterial disease [140,141]. Statins block the enzyme necessary for the production of L-mevalonate, an intermediary product in cholesterol synthesis. One of the main actions of statins is to lower circulating cholesterol levels. Cholesterol is produced from acetoacetyl coenzyme A in a process consisting of 28 steps. Statins block the second step, the conversion of 3-hydroxy-3-methylglutaryl coenzyme A (HMG-CoA) into Lmevalonate. This is also the rate-limiting step of cholesterol synthesis, and is catalysed by HMGCoA reductase. Lower levels of cholesterol prompt the cell to up-regulate the LDLreceptor. However, statin treatment also increases LDL-receptor degradation, so that the surface expression of the receptor remains unchanged. The receptor cycling is possibly in- 
creased, thus boosting the import of LDL-bound cholesterol into the cell and lowering the levels of circulating cholesterol as well [142].

Statin structure can be divided into three basic parts: an analogue of HMG-CoA, a hydrophobic ring structure that aids in binding to HMG-CoA reductase, and side groups on the rings. These side groups determine statin solubility and, as a result, many of the pharmacokinetic properties of statins. Atorvastatin, fluvastatin, lovastatin, pitavastatin, cerivastatin, and simvastatin are considered lipophilic, whereas pravastatin and rosuvastatin are considered hydrophilic as a result of polar side groups [140]. Although all statins can enter hepatic cells through either active or passive transport, hydrophilic statins, such as pravastatin and rosuvastatin are less likely to enter non-hepatic cells, while lipophilic statins, e.g. atorvastatin and simvastatin are more likely to enter hepatic and non-hepatic cells through passive diffusion. This difference in tissue permeability and metabolism may account for some of the differential pleiotropic effects among the statins [143,144]. Not all statins cross the bloodbrain barrier (BBB). Short-term statin treatment does not alter cholesterol levels in the brain. The more lipophobic statins such as pravastatin cannot cross the BBB. However, the lipophilic statins lovastatin and simvastatin are capable of such a crossing, although they reach only a relatively low concentration [145].

Recent compelling evidence suggests that the beneficial effects of statins may be due not only to their cholesterol-lowering effects, but also to their cholesterol-independent or pleiotropic effects $[140,142,143]$. These cholesterol-independent effects include improving endothelial function, attenuating vascular and myocardial remodelling, inhibiting vascular inflammation and oxidation, and stabilizing atherosclerotic plaques [144]. The mechanism underlying some of these pleitropic effects is to inhibit the conversion of HMG-CoA to Lmevalonic acid. This inhibition prevents the synthesis of important isoprenoid intermediates of the cholesterol biosynthetic pathway, such as farnesylpyrophosphate (FPP) and geranylgeranylpyrophosphate (GGPP) [146]. Both intermediates have indirect but important roles in vascular structure and function. These two isoprenoids are both used to provide proteins with lipophilic attachments to the cell membrane. Two protein families that require these lipophilic attachments for appropriate localization within the membrane and proper functional activity are the Ras and Rho families of small G proteins. Without modification of Ras by farnesylation and Rho by geranylgeranylation, neither protein can function properly or localize to its appropriate place within the cell membrane. Furthermore, both Ras and Rho are vital components of second messenger systems known to affect vascular inflammation, hypertrophy, and hyperplasia. These second messenger systems are also intimately involved in promoting vascular remodelling in disease states such as atherosclerosis and diabetes [140].

Hypercholesterolaemia interferes with endothelial function, resulting in impaired synthesis, release, and activity of endothelial NO [147]. The mechanism by which LDL-cholesterol (LDL-C) causes endothelial dysfunction and decreases NO bioactivity involves downregulation of endothelial NOS expression, diminished receptor-mediated NO release, and less NO 
bioavailability owing to greater ROS production [146]. LDL-C apheresis can improve endothelium-dependent vasodilatation, which indicates that statins could restore endothelial function, in part by lowering serum LDL-C levels. Cholesterol lowering alters atherosclerotic-plaque biology, thereby decreasing vascular inflammation and leukocyte activation. Thus, statins can improve endothelial function by lowering serum cholesterol levels. However, in some studies, statins improve endothelial function before significant change in serumcholesterol levels. Statins accelerate endothelial NO production by stimulating and upregulating endothelial NO synthase (eNOS), especially in the presence of hypoxia and oxidized LDL [147].

Statins affect eNOS expression and activity mainly through three mechanisms. First, statins increase eNOS expression by prolonging eNOS mRNA half-life rather than by inducing eNOS gene transcription. Second, statins reduce caveolin-1 abundance, an integral membrane protein that binds to eNOS in caveolae, thereby directly inhibiting NO production. Third, statins can activate the phosphatidylinositol 3-kinase (PI3K)/protein kinase Akt pathway. Akt is a serine/threonine kinase that regulates various cell functions, such as survival, growth and proliferation. Because Akt, in turn, phosphorylates and activates eNOS, statins can also increase eNOS activity through the PI3K/Akt pathway [146].

Statins may also improve endothelial function through their antioxidant effects. For example, statins enhance endothelium-dependent relaxation by inhibiting production of reactive oxygen species, such as superoxide and hydroxyl radicals, from aortas of cholesterol-fed rabbits [148]. Although lipid lowering by itself can reduce vascular oxidative stress, some of these antioxidant effects of statins appear to be cholesterol independent. Indeed, they can attenuate angiotensin II-induced production of the highly oxidative (free radical) species in VSMC and downregulate angiotensin-1 receptor expression. Because $\mathrm{NO}$ is scavenged by reactive oxygen species, these findings indicate that the antioxidant properties of statins may also contribute to their ability to improve endothelial function [147].

Vascular smooth-muscle cell migration and proliferation are two other major components of both atherogenesis and neointimal hyperplasia, and both of these components are affected by statin administration [140]. The small G proteins Ras and Rho, which play a large role in VSMC migration and proliferation, are plausible targets for the direct antiproliferative vascular effects of statins [143]. Statin administration is able to attenuate these effects of both small G-protein families [140]. Simvastatin inhibits both VSMC proliferation and migration in a series of experiments with human saphenous vein grafts [149].

In summary, statins could be beneficial not only for their lipid-lowering properties but for their other effects referred to as pleiotropic -that is, their capacity to restore endothelial function, to stabilize atherosclerotic plaque, or to alleviate oxidative stress and vascular inflammation [150-153]. Such effects have been demonstrated in rabbits fed cholesterol at a dose insufficient to reduce plasma-cholesterol levels [55,148]. 


\section{Choroidal changes induced by hypercholesterolaemia}

Few experimental studies examine the effects of hypercholesterolaemia on the posterior segment of the eye [154-159]. Hypercholesterolaemic rabbits constitute a useful model to delve into the repercussions of excess lipids at the ocular level. Rabbits fed a $0.5 \%$ cholesterol-enriched diet for 8 months showed a statistical increase in total serum cholesterol and in the sclera-choroid complex thickness in comparison to control $[6,157,158,160,161]$ (Figure 9).

The increased choroidal thickness is due mainly to clusters of lipid-charged macrophages (foam cells) which are surrounded by collagen fibres in the suprachoroid. In some instances, the foam cells and fibroblasts have ultrastructural features of necrosis, with a rupture of the cytomembranes. In addition, the clusters of foam cells are encircled by cholesterol clefts $[6,160]$ (Figure 10A). As a result of the lipid accumulation in the suprachoroid and in the large- and medium-size-vessel layers, the lumens of the choroidal vessels are mechanically compressed and the choroidal blood flow constricted (Figures 11B,12B). This situation also affects the choriocapillaris, which is compressed against Bruch's membrane, the capillary lumens being reduced to the point of collapse in some instances [6,160] (Figure 11B). However, the lumen reduction in the choroidal vessels of hypercholesterolaemic rabbit is due not only to the compression caused by the lipid build-up in the suprachoroid and vessel layers but to the changes of the VSMC and EC. The VSMC in the large- and medium-sized-vessel layer are hypertrophic with a compact appearance (Figure 12B), while EC in these layers and in the choriocapillaris show rarefactions in the cytoplasm that contribute to vascular lumen reduction (Figure 12B). The cytoplasm organelles show similar changes in VSMC and EC. The endoplasmic reticulum and Golgi cisterns are dilated, the ribosomes are disassembled, the mitochondria appear swollen, the caveolar system is smaller than in normal choroid (Figure 13A,E,F), and the cytoplasm contains droplets of lipids and dense bodies. In VSMC the myofilaments are disorganized, with areas of focal necrosis affecting the dense plaques (Figure 13F). In the areas where the tissue was highly disorganized, other necrotic features (swelling, vacuolization, cytomembrane necrosis, and the disappearance of specific ultrastructural characteristics) are visible in both cell types [6,160] (Figure 13E,F).

The endothelial alterations described above could be explained, at least partly, by the Posieulle's law, which states that tangential tension is directly proportional to the bloodflow viscosity and inversely proportional to the third power of the inside radius. Accordingly, reduction of the choroidal vascular lumens in hypercholesterolaemic rabbits could increase the local tangential force exerted by the choroidal blood flow on the vessel walls. With time, these changes in blood flow could lead to a reorganization of the endothelial phenotype, resulting in endothelial dysfunction [162]. Endothelial changes and basalmembrane thickening of ocular vessels in hypercholesterolaemic rabbits may precede the atherosclerotic process. In the hypercholesterolaemic rabbits, the basal membrane of EC and VSMC contained electrodense and electrolucent particles and were thicker than in the normal choroid. 
In the atherosclerotic process, the adhesion molecules VCAM-1 and ICAM-1 favour monocyte binding and migration to the subendothelial space, where they transform into macrophages [3,4]. In iris arterioles of hypercholesterolaemic rabbits, the internalization of lipids by macrophages results in the formation of foam cells [163]. Foam cells are also found in the suprachoroid and large- and medium-sized-vessel layers of hypercholesterolaemic rabbits $[6,160]$. Before and after dying, foam cells may release products such as cholesterol (oxidized and esterified) that increase endothelial damage, thus encouraging the atherosclerotic lesion. The foam cells underneath the basal membrane of the large-sized-vessel layer [6,160], where the vessels have a diameter of up to $90 \mu \mathrm{m}$ [15], could represent the microatheromas described in brain circulation [164]. In the medium-sized-vessel layer, arterioles with diameters ranging from 20 to 40 micrometers [15], combined with the increased collagen detected in the adventitia and the lipid deposits (electron-dense vesicles) inside muscle cells $[6,160]$, could produce arteriolar hyalinosis [164].

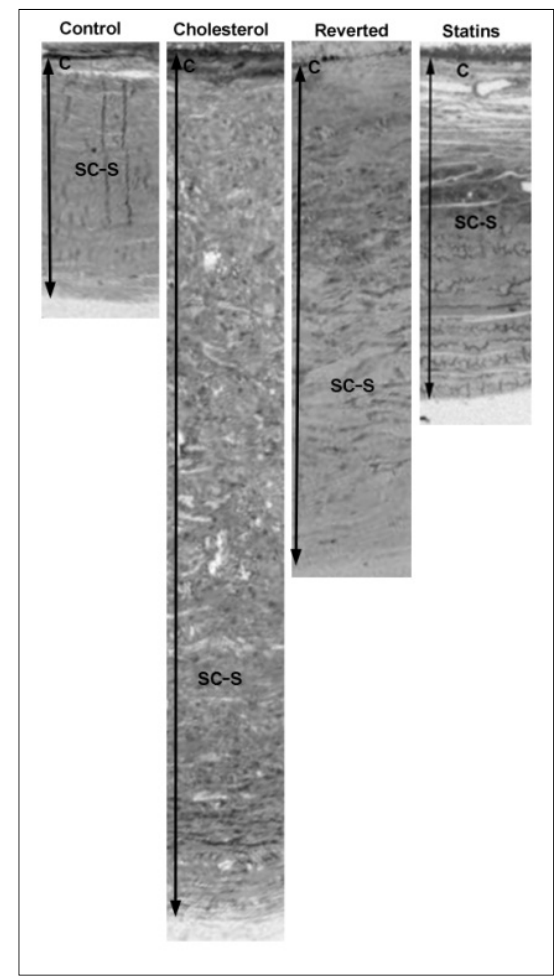

Figure 9. Thickening of the sclera-choroid complex (double arrow) in the study groups. Semithin sections (toluidine blue).(C: vascular layers of the choroid; SC-S: suprachoroidea-sclera). [Control: standard diet; Hypercholesterolemic: $0.5 \%$ cholesterol-enriched diet for 8 months; Reverted: $0.5 \%$ cholesterolenriched diet for 8 months plus standard diet for another 6 months; Statins: Hypercholesterolemic diet + fluvastatin sodium or pravastatin sodium for 8 months]. Scale bar, $100 \mu \mathrm{m}$. (Modified from Salazar et al [6] and Rojas et al. [55]). 

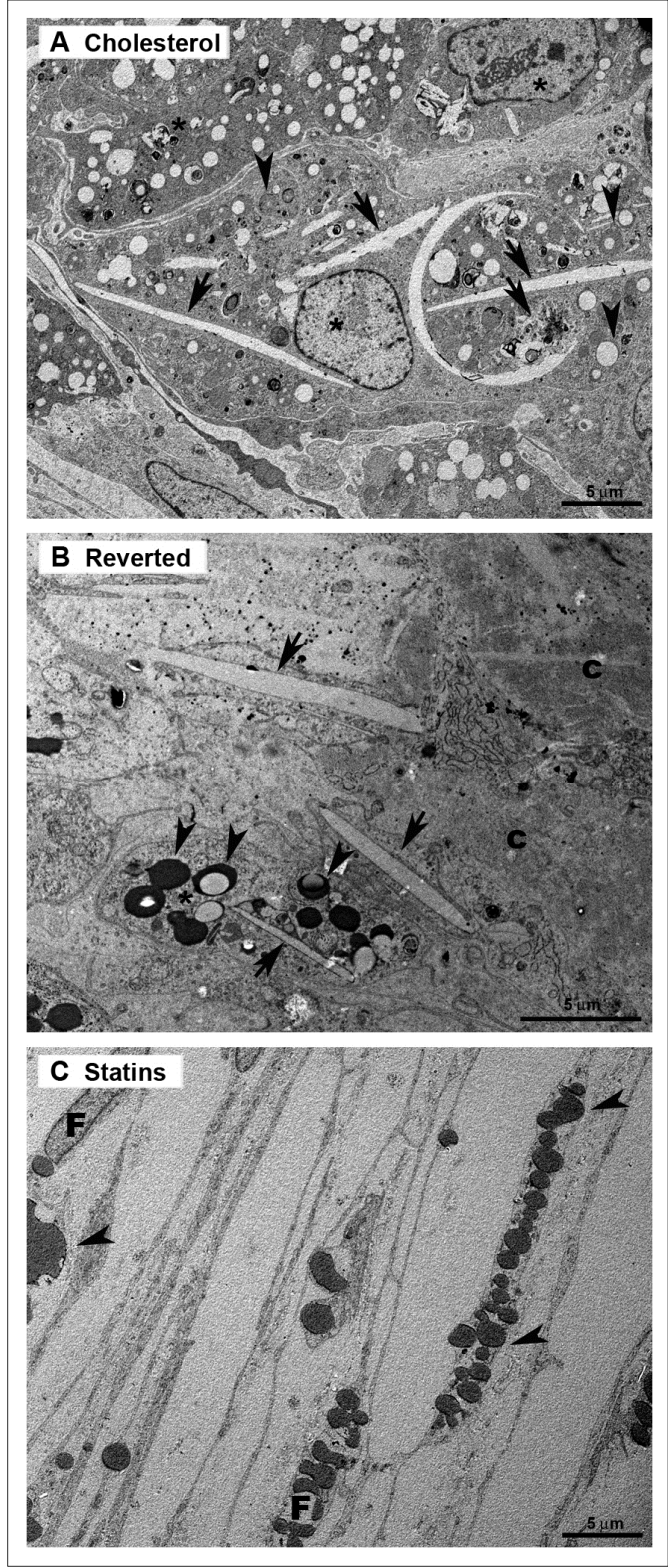

Figure 10. Electron micrographs of the suprachoroidea. A: Hypercholesterolemic rabbit. The image shows a large amount of lipid containing foam cells as well as collagen fibers and cholesterol clefts between them. B: Reverted animals. The collagen fibres predominate over the foam cells and cholesterol clefts. C: Statin-treated animals. An increase in collagen is observed. The lipids are located mainly inside the fibroblast. [Foam cells (asterisk); lipids (arrowhead); cholesterol clefts (arrow); collagen (C); fibroblast (F)]. Scale bars: $5 \mu \mathrm{m}$. (Image B from Salazar et al. [6]). 


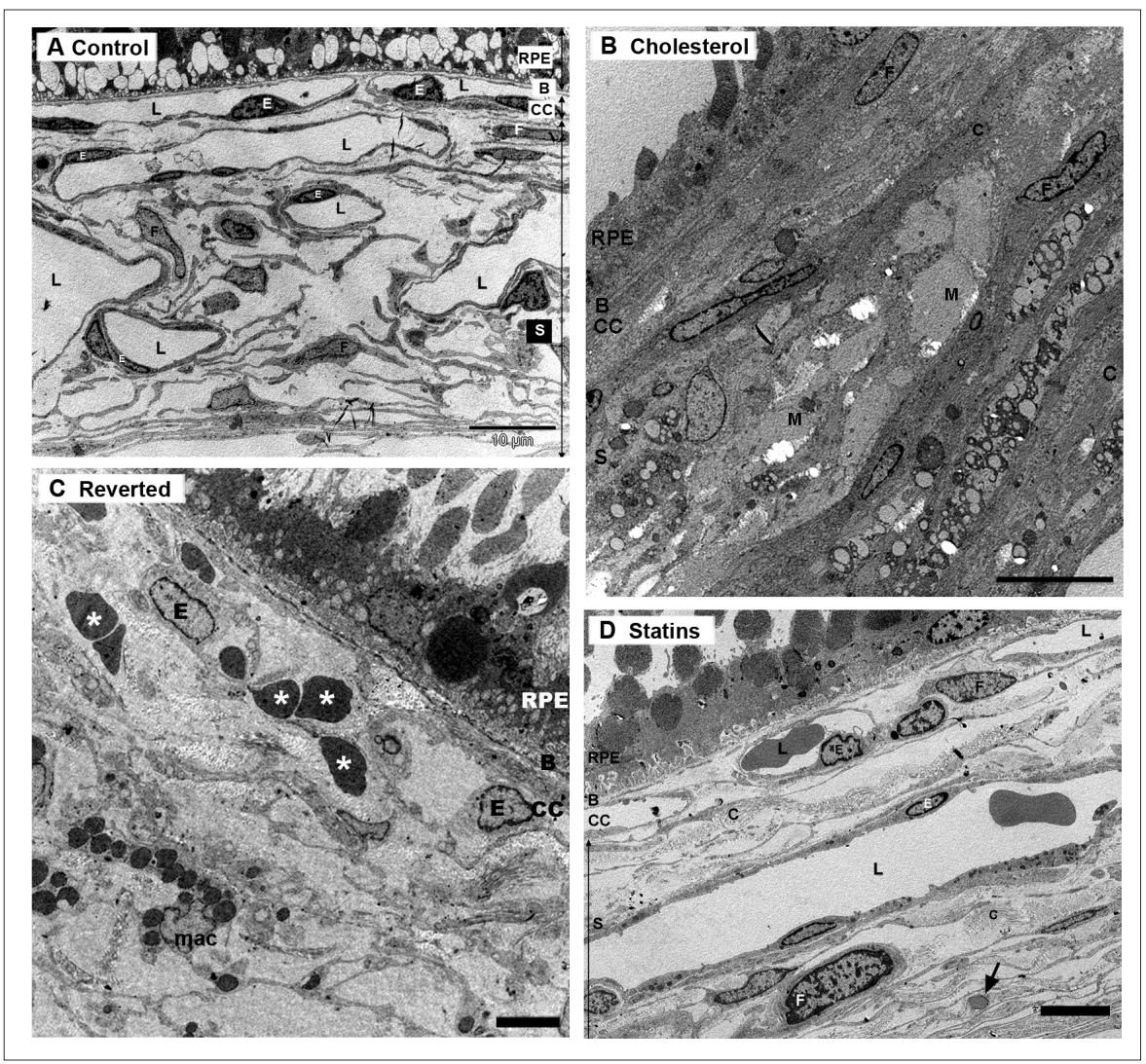

Figure 11. Electron micrographs of large- and medium sized-vessel layers and choriocapillaris. A: Spongy structure of the choroid of a control animal. B: In the hypercholesterolemic group the vascular lumens were reduced to the point of collapse in some instances. C: In the reverted animals, choroidal changes make difficult to differentiate the choroidal layers. D: The vascular lumens of statin-treated animals were opened in part due to the reduction of suprachoroidal lipids. [Bruch's membrane (B); collagen (C); choriocapillaris (CC); endothelial cell (E); fibroblast (F); vascular lumen (L); lipids (arrow); vascular smooth-muscle cells (M); retinal-pigment epithelium (RPE); large- and medium-sized vessel layers (S); Red blood cells (*) outside the vascular lumens; macrophage (mac)]. [Bars: A,B, $10 \mu \mathrm{m}$; C,D 5 $\mu \mathrm{m}$ ]. (Modified from Salazar et al [6] and Rojas et al. [55]).

Studies examining the aortic preparations of hypercholesterolaemic rabbits indicate that, at sites where the luminal side was covered by fatty streaks, the number of caveolae in the EC was significantly lower [165]. Caveolae are distinctive cholesterol-enriched invaginations of the plasma membrane of the most mammalian cells. Caveolin is an essential component of caveolas, and their expression in cells results in the assembly of caveolae at the cell surface. There is an emerging role of caveolae, in organizing and modulating the basic functions of smooth muscles [166] and vascular functions dependent on $\mathrm{NO}$ and $\mathrm{Ca}^{2}+$ signalling $[166,167]$. Caveolin proteins tightly bind cholesterol and contribute to the regulation of cho- 
lesterol fluxes and distribution within cells [168]. It has been reported that in the early stages of hypercholesterolaemia, caveolin-1 synthesis increases to remove the excess cholesterol from the cells. However, after long periods of cholesterol feeding, caveolin-1 synthesis was repressed [169]. In [95] reported the cholesterol-induced impairment of NO production through the modulation of caveolin abundance in EC as a mechanism that may be involved in the pathogenesis of endothelial dysfunction. In hypertensive rats, it has been postulated that a decreased number of caveolae could be the reason for the impaired relaxation by NO donors. Additionally, in rabbits, after a long period (12 weeks) of ingesting a high-cholesterol diet, both the level of caveolin-1 and the activity of NOS declined [169]. EC and VSMC in hypercholesterolaemic rabbits (8 months of hypercholesterolaemic diet) exhibit less caveolae than did control animals (Figure 13A,F), a situation that could contribute to the deposit of circulating molecules, such as LDL, which are detected as electrolucent or electrodense particles of varying size. A decrease in caveola abundance has been postulated to represent a novel mechanism of endothelial dysfunction in atheromatous rabbit aorta $[165,170]$. This idea is supported by the fact that a pharmacological disruption of endothelial caveolae also results in the attenuation of acetylcholine-induced relaxation $[165,170]$.

\section{Choroidal changes after diet-induced normalization of plasma lipid levels}

It has been established that the atherosclerotic lesions can undergo regression in experimental animals such as rabbits, dogs, and non-human primates [171]; and the lack of progression or even regression can occur in humans, especially with the introduction of new therapeutical options [172].

Knowledge of the changes arising after the normalization of the cholesterol values in a vascular tissue such as the choroid can be useful to evaluate the effects of the different drugs for hypocholesterolaemia. Animal models offer a useful tool for studying lesion regression after cholesterol-serum values normalize. When excessive cholesterol is withdrawn from the diet of rabbits, these animals recover some of the biochemical and histological parameters that are altered in cholesterol-fed animals [6,173]. It has been reported that the serum concentration of total cholesterol, triglycerides, phospholipids, VLDL, HDL, LDL, and intermediate-density lipoprotein (IDL) increased in rabbits fed a $0.5 \%$ cholesterol-enriched diet for 8 months. When the same animals were then fed a standard diet for another 6 months, (reverted animals), lipid values returned to normal. Notably, the normalization of serum values was not followed by a complete recovery of the histology of the retina [158], choroid, or thoracic aorta [6]. In reverted rabbits, the sclera-choroid complex thinned compared with that of hypercholesterolaemic animals, due to having far fewer clusters of foam cells encircled by cholesterol clefts in the suprachoroid (Figure 9). However, these tissues had not yet reached the normal thickness values of control due to the increase in collagen fibres [6] (Figures 10B,11C). This marked reduction in the suprachoroidal build-up of lipids implies less compression of the vessels. Such findings have also been reported in the iris and cornea of hypercholesterolaemic reverted rabbits [174]. However, although in 
most cases fewer lipids were found in the suprachoroidal spaces in reverted rabbits, there were still numerous ultrastructural changes in comparison with hypercholesterolaemic and normal rabbits. These changes could contribute to chronic ischaemia, for several reasons: i) The large- and medium-sized-vessel layers still exhibited alterations in VSMC and EC that could impair vascular function. Specifically, the cytoplasm organelles (endoplasmic reticulum, Golgi cisterns, ribosomes, mitochondria, and caveolar system) of VSMC and EC in the reverted rabbits showed changes similar to hypercholesterolaemic animals. Also, in zones where the tissue was highly disorganized, necrotic features (swelling, vacuolization, cytomembrane necrosis, and disappearance of specific ultrastructural characteristics) were noted [6] (Figures 11C,12C). ii) The EC of the choriocapillaris extended cytoplasmic projections that reduced the vascular lumen (Figure 12C). iii) Finally, the intervascular spaces of the choroid contained fewer lipids than in hypercholesterolaemic animals but more collagen fibres than in control (Figures 11A,C,12A,C).

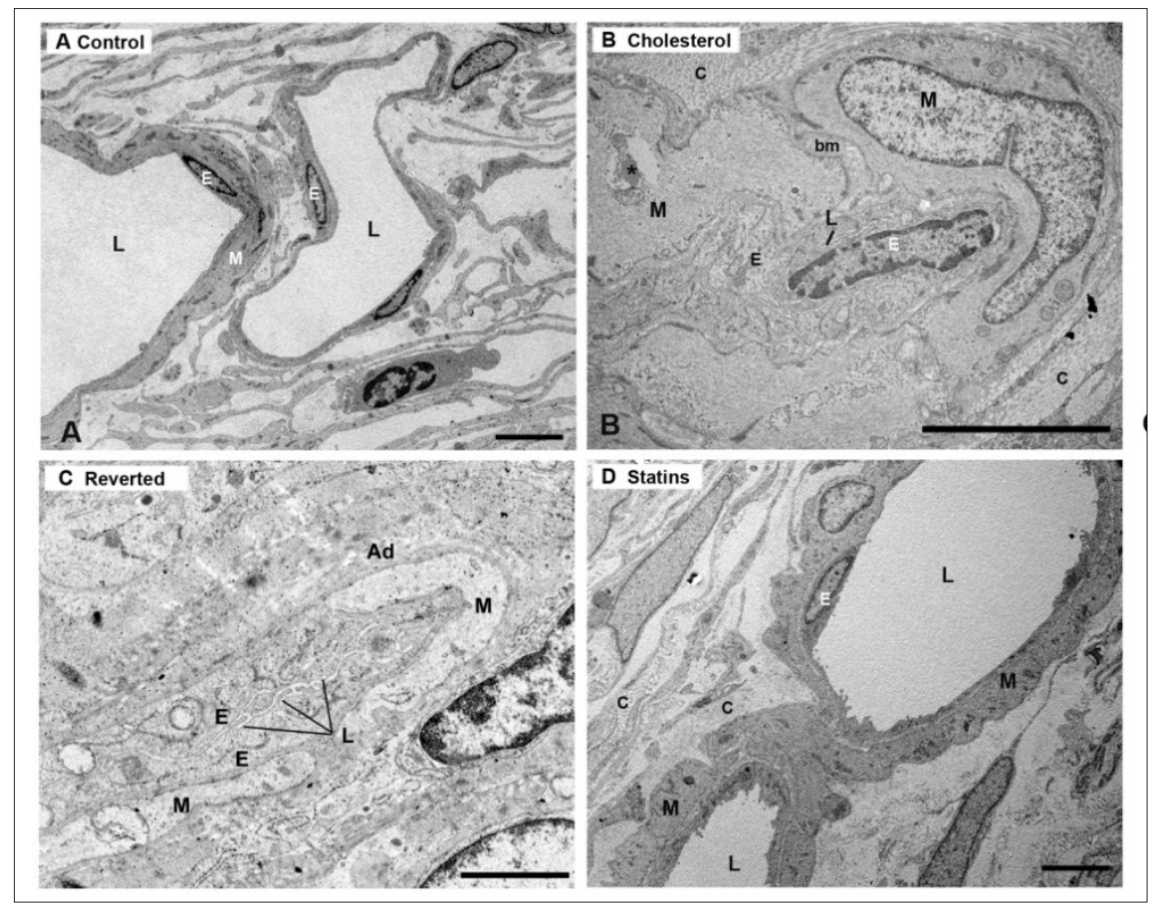

Figure 12. Electron micrographs of large- and medium sized-vessel layers of the choroid. A: Control animals. B: In the hypercholesterolemic animals the vascular lumens are reduced. The muscle cells are hypertrophic and contain drops of lipids $\left(^{*}\right)$ in the cytoplasm. Additionally, the endothelial cells are hypertrophic and/or necrotic. The basal membrane is thick. C: Reverted animals maintained the reduction of the vascular lumen and the thickening of the adventitia. D: In animals treated with statins vascular lumens, vascular smooth-muscle cells, endothelial cells and basal membrane were more similar to the control group. [collagen $(C)$; endothelial cell (E); vascular lumen (L); vascular smooth-muscle cells (M); basal membrane (bm); adventitia (Ad)]. [Bars: A,B, D $5 \mu \mathrm{m}$; C $2 \mu \mathrm{m}$ ]. (Modified from Salazar et al [6] and Rojas et al. [55]). 
This increase in collagen fibres was also found in the intima, among VSMC and in the adventitia (Figure 12C) of the large- and medium-sized-vessel layer and in the basal membrane of the EC of the choriocapillaris [6]. It is well known that the reabsorption of both esterified and free cholesterol is followed by intense sclerogenic activity [175], due to the capacity of cholesterols and their esters to induce inflammation. Some inflammatory cytokines (TNF $\alpha$ and IL-1) control the remodelling activity of macrophages and smooth-muscle cells, which have the capacity to produce several matrix metalloproteinases (MMPs) $[176,177]$. It has been observed that such MMPs are synthesised mainly where the concentration of foam cells is greatest and that there is a relationship between lipid uptake and MMP activity [177]. The observations cited above underline the strong connection between inflammation, tissue remodelling, and lipid metabolism.

In summary, in hypercholesterolaemic rabbits the replacement of a hyperlipidaemic diet by a standard one normalized serum-lipid levels and eliminated most lipid build-up in the posterior segment of the eye. However, this lipid reduction was not followed by a reversal of the changes in choroidal vessels, where persisting ultrastructural changes in VSMC, EC, and extracellular matrix were compatible with a chronic ischaemia.

\section{Choroidal changes after low-dose statin treatment}

As mentioned above, it is well known that statins can exert cholesterol-independent or pleitropic effects which involve the restoration of endothelial function, stabilization of the atheromatous plaque, reduced oxidative stress, lower vascular inflammation, immunomodulation, and inhibition of VSMC proliferation [146,150,153,178]. Fluvastatin sodium (a lipophilic synthetic statin metabolised by the liver) and pravastatin sodium (a hydrophilic statin of fungal origin) can induce the regression of atherosclerosis besides reducing plasma cholesterol $[148,179]$.

It has been reported that $2 \mathrm{mg} / \mathrm{kg} /$ day of fluvastatin sodium and pravastatin sodium exerts an anti-atherosclerotic effect that appeared not to be mediated by the lipid-lowering properties of the drugs [150,180,181]. A $12.5-50 \mathrm{mg} / \mathrm{Kg} /$ day dosage of fluvastatin effectively reduces plasma lipids in Watanabe heritable hyperlipidaemic rabbits [182]. On the contrary, 2 $\mathrm{mg} / \mathrm{Kg} /$ day of fluvastatin did not lower plasma-cholesterol levels but did contribute to the impaired endothelium-dependent relaxation response in aortic rings [148] and femoral arteries of cholesterol-fed rabbits [150].

According with reference [148], hypercholesterolaemic rabbits treated with fluvastatin sodium and pravastatin sodium at a non-lipid-lowering dosage $(2 \mathrm{mg} / \mathrm{kg} /$ day $)$ showed a very small descent in plasma cholesterol and triglycerides levels [55]. In comparison with hypercholesterolaemic rabbits, low-dose statin-treated animals had far fewer lipids in the suprachoroid (the foam cells were decreased or absent), triggering a significant thinning of the sclera-suprachoroid complex $(\mathrm{p}<0.000)$ (Figure 9). This reduction in the build-up of lipids relieved the mechanical compression of the vascular layers of the choroid and lead to normalization of the spongy texture of the choroid [55] (Figure 11D). However, statin-treated 
animals bore some alterations not present in control animals, such as clumps of electrodense particles, some foam cells, and fibroblast-containing lipids in the suprachoroid (Figure $10 \mathrm{C}$ ) or a significant thickening of the vascular layers because the vascular lumens were open [55] (Figures 11D,12D). The lack of lumen closure in low-dose statin-treated rabbits (unlike that observed in hypercholesterolaemic rabbits) suggests that the choroidal blood flow was not compromised and that endothelial dysfunction would not result in part because of the lesser stress on EC by means of a weakening of the local tangential forces exerted on the vessel walls when the inner vascular radius decreased [55]. In addition, in low-dose statin-treated animals, signs of necrosis were rarely found (Figure 13B,C), the EC looked similar to those of control (Figure 13A-D), the cytoplasmic organelles were normal (Figure 13B,D), and the caveolar system was more numerous than in hypercholesterolaemic rabbits [55] (Figure 13B,D-F). This increment of caveolae detected in the lowdose statin-treated animals could account for the better preservation of endothelial function and could contribute to the normalization of vascular lumens observed in these animals. It has been proposed that caveolae could be specialized plasmalemmal regions involved in the integration of extracellular contractile signals and intracellular effectors in VSMC [183]. Three findings in low-dose statin-treated rabbits led to speculation that treatment improved VSMC function: first, the increased amount of caveolae observed and their location close to the underlying network of peripheral sarcoplasmic reticulum; second, VSMC were not hypertrophic and exhibited the elongated shape observed during relaxation [55]. This contrasted with the compact, round, and short shape exhibited by VSMC in hypercholesterolaemic rabbits, which was compatible with a contractile state; and third, the absence of areas of focal necrosis related to the dense plaques in low-dose statin animals.

A noteworthy finding in the cytoplasm of the EC and VSMC in the low-dose statin-treated group was that the cytoplasmic organelles were normal. Particularly the mitochondria maintained a normal electrodensity of the matrix, and the cristae and membranes were well preserved (Figure 13D). This is of outstanding importance, taking into account that these organelles represent a fundamental structure in the aerobic metabolism [184] and that they are extremely sensitive to hypoxia. The importance of mitochondria is well known in oxidative phosphorylation to generate ATP. Mitochondrial phosphorylation is impaired in ischaemic situations and, as a consequence of oxidative stress, DNA, proteins, and lipids, is damaged by a surge in free radicals [185]. From the mitochondrial integrity found in low-dose statin-treated rabbits, good functioning of EC and VSMC could be deduced. The normal ultrastructure of EC and VSMC suggests that the endotheliumdepending relaxation is maintained, thus reducing the ischaemia. According to ultrastructural examinations in the choroidal vascular tissue, the effects of low-dose statins are probably mediated by an overregulation of the endothelial NO and a downregulation of endothelin-1, as reported in studies on the direct consequences of the endothelial dysfunction in extraocular tissues [180]. This hypothesis should be tested by functional studies on ocular vascular reactivity. Another remarkable observation in low-dose statin-treated rabbits was that the basal membranes resembled control. However, it should be men- 
tioned that an increase in collagen fibres in the vascular adventitia and in the intervascular spaces, and even fibroblast containing clumps of lipids could still be detected (Figures 11D,12D). These features can be explained firstly by the low lipid-decreasing capability of statins at the dosage of $2 \mathrm{mg} / \mathrm{kg} /$ day used in the study and, secondly, to macrophage activity and their ability to produce MMPs $[176,177]$ in the areas of higher concentrations of foam cells, where esterified and free-cholesterol reabsorption is followed by sclerogenic activity [175].

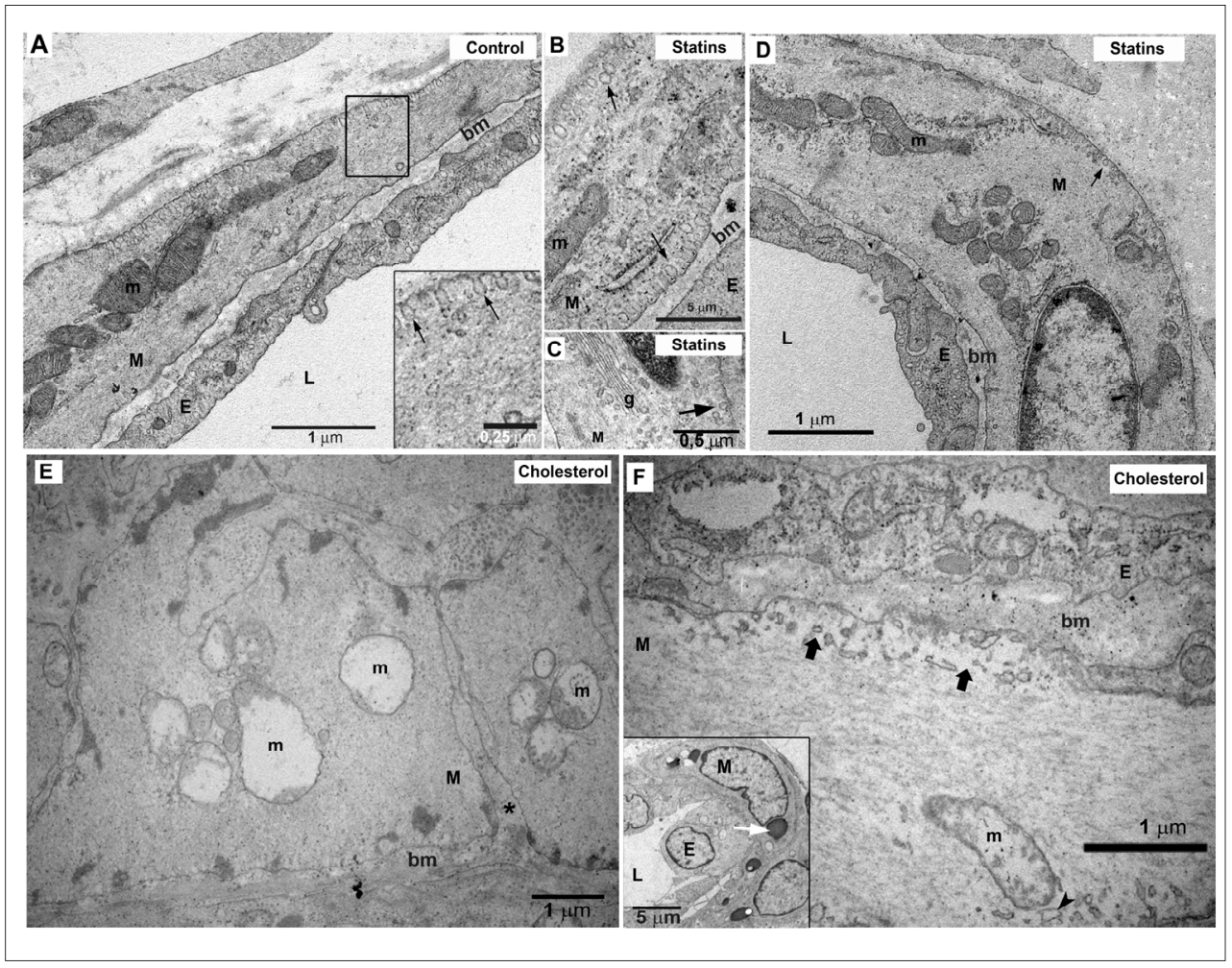

Figure 13. Electron micrographs of endothelial and vascular smooth-vessel cells (VSMC). A: Control animal. The insert shows the normal ultrastructure of the myofilaments and caveolar system. B, C, D: Statin-treated rabbits. B,C: Intact caveolar system and cytoplasmic organelles. D: Elongated VSMC with well-preserved mitochondria, caveolae, and peripheral sarcoplasmic reticulum. The nucleus and perinuclear cisterns are normal. E, F: Hypercholesterolemic rabbits. E: Rounded and hypertrophic VSMC. Swollen mitochondria with loss of the cristae. The caveolae are decreased and the intercellular space increased (asterisk) in some instances. F: Area of focal necrosis below the plasma membrane (large black arrow). Dilated endoplasmic reticulum (arrowhead). The myofilaments are disorganized. Drops of lipids (white arrow) in VSMC (insert). [basal membrane (bm); endothelial cell (E); Golgi (g); vascular lumen (L); vascular smooth muscle cells (M); mitochondria (m); Caveolae (small black arrow)]. [Scale bars: A,D,E,F, $1 \mu \mathrm{m}$; A insert, $0.25 \mu \mathrm{m}$; B,F insert $5 \mu \mathrm{m}$; C, $0.5 \mu \mathrm{m}$.]. (From Rojas et al. [55]) 
In hypercholesterolaemic New Zealand rabbits, treatment with fluvastatin sodium and pravastatin sodium at a dose $(2 \mathrm{mg} / \mathrm{Kg} /$ day $)$ insufficient to normalize plasma-lipid levels prevents the progression of atherosclerosis in the different vascular layers of the choroid; the most striking effects being seen in EC and VSMC.

\title{
9. Conclusions and perspectives
}

Clinical studies have suggested that hyperlipidaemia alone can prompt structural changes in the choroidal vascular and retinal system that, over time, could provoke retinal dysfunction. This situation of chronic ischaemia is also present in causes of blindness as prevalent as aged-related macular degeneration, glaucoma or diabetic retinopathy [11-13]. This situation is extremely important, as today we know from epidemiological studies the relation between vascular retinal lesions and the incidence of lesions in non-ocular tissues that appear to be linked to common factors having microvascular effects. Statins are cholesterol-lowering medications. The treatment of hypercholesterolaemic rabbits with a non-lipid-lowering dose of statins dramatically reduces the ultrastructural choroidal damage induced by a sustained cholesterol-enriched diet [55]. This implies better choroidal flow and consequently oxygenation of the external retina, reducing chronic ischaemia [157]. It is well known that statins can exert cholesterol-independent or pleitropic effects [11] which involve the restoration of endothelial function, stabilization of atheromatous plaque, reduced oxidative stress, or lower eye inflammation [150,153,178]. These effects are potentially decisive in maintaining normal endothelial and smooth-muscle function and in improving endothelium-dependent relaxation. It bears noting that the most striking effects of low-dose statins in hypercholesterolaemic rabbits are the normalization of the ultrastructure of EC and VSMC, specifically cytoplasm organelles and caveolar system. Such effects suggest a possible role of statins in those ocular diseases having endothelial dysfunction in their physiopathology such as AMD, glaucoma or diabetic retinopathy, among others.

\section{Author's details}

\author{
J.M. Ramírez * \\ Instituto de Investigaciones Oftalmológicas Ramón Castroviejo, \\ Universidad Complutense de Madrid, Madrid, Spain \\ Departamento de Oftalmología, Facultad de Medicina, \\ Universidad Complutense de Madrid, Madrid, Spain \\ J.J. Salazar \\ Instituto de Investigaciones Oftalmológicas Ramón Castroviejo, \\ Universidad Complutense de Madrid, Madrid, Spain \\ Escuela Universitaria de Óptica, Universidad Complutense de Madrid, Madrid, Spain
}

${ }^{*}$ Corresponding Author 
R. de Hoz

Instituto de Investigaciones Oftalmológicas Ramón Castroviejo,

Universidad Complutense de Madrid, Madrid, Spain

Escuela Universitaria de Óptica, Universidad Complutense de Madrid, Madrid, Spain

B. Rojas

Instituto de Investigaciones Oftalmológicas Ramón Castroviejo,

Universidad Complutense de Madrid, Madrid, Spain

Departamento de Oftalmología, Facultad de Medicina,

Universidad Complutense de Madrid, Madrid, Spain

B.I. Gallego

Instituto de Investigaciones Oftalmológicas Ramón Castroviejo,

Universidad Complutense de Madrid, Madrid, Spain

Escuela Universitaria de Óptica, Universidad Complutense de Madrid, Madrid, Spain

A.I Ramírez

Instituto de Investigaciones Oftalmológicas Ramón Castroviejo,

Universidad Complutense de Madrid, Madrid, Spain

Escuela Universitaria de Óptica, Universidad Complutense de Madrid, Madrid, Spain

A. Triviño

Instituto de Investigaciones Oftalmológicas Ramón Castroviejo,

Universidad Complutense de Madrid, Madrid, Spain

Departamento de Oftalmología, Facultad de Medicina,

Universidad Complutense de Madrid, Madrid, Spain

\section{Acknowledgement}

The authors would like to thank David Nesbitt for correcting the English version of this work. This work was supported by RETICs Patología Ocular del Envejecimiento, Calidad Visual y Calidad de Vida (Grant ISCIII RD07/0062/0000, Spanish Ministry of Science and Innovation); Fundación Mutua Madrileña (Grant 4131173); BSCH-UCM GR35/10-A Programa de Grupos de Investigación Santander-UCM. Beatriz Gallego is currently supported by a predoctoral fellowship from the Universidad Complutense de Madrid.

\section{References}

[1] Bill A, Sperber GO. Control of retinal and choroidal blood flow. Eye (London, England) 1990;4(Pt 2) 319-325.

[2] Chen Y, Chang Y, Jyh Jiang M. Monocyte chemotactic protein-1 gene and protein expression in atherogenesis of hypercholesterolemic rabbits. Atherosclerosis 1999;143(1) 115123. 
[3] Ross R. Atherosclerosis - An Inflammatory Disease. New England Journal of Medicine 1999;340(2)15-126.

[4] Crispin S. Ocular lipid deposition and hyperlipoproteinaemia. Progress in Retinal and Eye Research 2002;21(2) 169-224.

[5] Rong JX, Shen L, Chang YH, Richters A, Hodis HN, Sevanian A. Cholesterol Oxidation Products Induce Vascular Foam Cell Lesion Formation in Hypercholesterolemic New Zealand White Rabbits. Arteriosclerosis, Thrombosis, and Vascular Biology 1999;19(9) 2179-2188.

[6] Salazar JJ, Ramírez AI, de Hoz R, Rojas B, Ruiz E, Tejerina T, Triviño A, Ramírez JM. Alterations in the choroid in hypercholesterolemic rabbits: reversibility after normalization of cholesterol levels. Experimental Eye Research 2007 ;84(3) 412-422.

[7] Martínez-González J, Llorente-Cortés V, Badimon L. Biología celular y molecular de las lesiones ateroscleróticas. Revista Española de Cardiología 2001;54 218-231.

[8] Schneider DB, Vassalli G, Wen S, Driscoll RM, Sassani AB, DeYoung MB, Linnemann R, Virmani R, Dichek DA. Expression of Fas Ligand in Arteries of Hypercholesterolemic Rabbits Accelerates Atherosclerotic Lesion Formation. Arteriosclerosis, Thrombosis, and Vascular Biology 2000;20(2) 298-308.

[9] Öörni K, Pentikäinen MO, Ala-Korpela M, Kovanen PT. Aggregation, fusion, and vesicle formation of modified low density lipoprotein particles: molecular mechanisms and effects on matrix interactions. Journal of Lipid Research 2000;41(11) 1703-1714.

[10] Klein R, Sharrett AR, Klein BEK, Chambless LE, Cooper LS, Hubbard LD, Evans G. Are Retinal Arteriolar Abnormalities Related to Atherosclerosis?: The Atherosclerosis Risk in Communities Study. Arteriosclerosis, Thrombosis, and Vascular Biology 2000;20(6) 1644-1650.

[11] Wong TY, Klein R, Couper DJ, Cooper LS, Shahar E, Hubbard LD, Wofford MR, Sharrett AR. Retinal microvascular abnormalities and incident stroke: the Atherosclerosis Risk in Communities Study. Lancet 2001;358(9288) 1134-1140.

[12] Klein R, Klein BEK, Tomany SC, Wong TY. The relation of retinal microvascular characteristics to age-related eye disease: the Beaver Dam eye study. American Journal of Ophthalmology 2004;137(3) 435-444.

[13] Wong TY, McIntosh R. Systemic associations of retinal microvascular signs: a review of recent population-based studies. Ophthalmic and Physiological Optics 2005;25(3) 195204.

[14] Matsusaka T. Cytoarchitecture of choroidal melanocytes. Experimental Eye Research 1982;35(5) 461-469.

[15] Hogan MJ, Alvarado JA, Weddell JE. Histology of the human eye: an atlas and textbook. Toronto: W.B. Saunders Company Ed; 1971.

[16] Tamm ER, Flügel-Koch C, Mayer B, Lütjen-Drecoll E. Nerve cells in the human ciliary muscle: ultrastructural and immunocytochemical characterization. Investigative Ophthalmology \& Visual Science 1995;36(2) 414-426.

[17] Poukens V, Glasgow BJ, Demer JL. Nonvascular contractile cells in sclera and choroid of humans and monkeys. Investigative Ophthalmology \& Visual Science 1998;39(10) 1765-1774. 
[18] Flügel-Koch C, May CA, Lütjen-Drecoll E. Presence of a contractile cell network in the human choroid. Ophthalmologica. 1996;210(5) 296-302.

[19] Ramírez JM, Triviño A, De Hoz R, Ramírez AI, Salazar JJ, García-Sánchez J. Immunohistochemical study of rabbit choroidal innervation. Vision Research 1999;39(7) 12491262.

[20] Triviño A, De Hoz R, Salazar JJ, Ramírez AI, Rojas B, Ramírez JM. Distribution and organization of the nerve fiber and ganglion cells of the human choroid. Anatomy and Embryology 2002;205(5-6) 417-430.

[21] Triviño A, de Hoz R, Rojas B, Salazar JJ, Ramírez AI, Ramírez JM. NPY and TH innervation in human choroidal whole-mounts. Histology and Histopathology 2005;20(2) 393402.

[22] Triviño A, Ramírez JM. Anatomofisiología de la coroides. In: Gómez-Ulla F, Marín F, Ramírez JM, Triviño A. (ed) La circulación coroidea. Barcelona: EDIKA-MED. S.A; 1989. p7-29.

[23] Bron AJ, Tripathi RC, Tripathi BJ. The choroid and uveal vessels. In: Bron AJ, Tripathi RC, Tripathi BJ. (ed) Wolff's Anatomy of the Eye and Orbit (Eighth edition). London: Chapman \& Hall Medical; 1997. p371-410.

[24] Riva CE, Alm A, Pournaras CJ. Ocular circulation. In: Levin LA, Nilsson SFE, Ver Hoeve J, Wu SM, Kaufman PL, Alm A. (ed) Adler's Physiology of the Eye. Edinburgh: Elsevier Saunders; 2011. p243-273.

[25] Hayreh SS. The long posterior ciliary arteries. An experimental study. Albrecht von Graefes Archiv fur Klinische und Experimentelle Ophthalmologie 1974;192(3) 197-213.

[26] Ducournau DH. A new technique for the anatomical study of the choroidal blood vessels. Ophthalmologica. 1982;184(4) 190-197.

[27] Triviño A, Ramírez JM, García-Sánchez J. Study of the choroidal circulation in the human eye: experimental model. In: Flower RW. (ed) II Internacional Symposium on the Choroid. Maryland (USA); 1989. p32-42.

[28] Risco JM, Grimson BS, Johnson PT. Angioarchitecture of the Ciliary Artery Circulation of the Posterior Pole. Archives of Ophthalmology 1981;99(5) 864-868.

[29] Hayreh SS. Submacular choroidal vascular pattern. Experimental fluorescein fundus angiographic studies. Albrecht von Graefes Archiv fur Klinische und Experimentelle Ophthalmologie. 1974;192(3) 181-196.

[30] Shimizu K, Ujiie K. Morphology of the submacular choroid: vascular structure. Ophthalmologica. 1981;183(1) 5-10.

[31] Weiter JJ, Ernest JT. Anatomy of the choroidal vasculature. American Journal of Ophthalmology 1974;78(4) 583-590.

[32] Ramírez JM, Triviño A, De Hoz R, González C, Borrego R, Salazar JJ, García-Sanchez J. Estudio de la vascularización ciliar en el conejo albino. Archivos de la Sociedad Española de Oftalmología 1990;5 823-30.

[33] Buggage RR, Torcynski E, Grossniklaus HE. The uveal tract. In: Duane TD, Jaeger EA. (ed) Biomedical Foundations of Ophathalmology. CD-Rom. Philadelphia: Harper \& Row Publishers; 2004. 
[34] Olver JM, Sharma A. Anatomy and physiology of the uveal tract. In: Easty JM, Sparrow JM. (ed) Oxford Textbook of Ophthalmology. New York: Oxford Medical Publications; 1999. p501-508.

[35] Fryczkowski AW, Sherman MD, Walker J. Observations on the lobular organization of the human choriocapillaris. International Ophthalmology 1991;15(2) 109-120.

[36] Triviño A, Ramírez JM, García-Sánchez J. Estudio comparativo entre la vascularización coroidea del hombre y el animal de experimentación. Archivos de la Sociedad Española de Oftalmología 1986;51 305-312.

[37] Spitznas M. The fine structure of the chorioretinal border tissues of the adult human eye. Advances in Ophthalmology 1974; 2878-174.

[38] Spitznas M, Reale E. Fracture faces of fenestrations and junctions of endothelial cells in human choroidal vessels. Investigative Ophthalmology 1975; 14(2) 98-107.

[39] Melamed S, Ben-Sira I, Ben-Shaul Y. Ultrastructure of fenestrations in endothelial choriocapillaries of the rabbit--a freeze-fracturing study. British Journal of Ophthalmology 1980;64(7) 537-543.

[40] Bill A, Tornquist P, Alm A. Permeability of the intraocular blood vessels. Transactions of the Ophthalmological Societies of the United Kingdom 1980;100(3) 332-336.

[41] Törnquist P. Capillary permeability in cat choroid, studied with the single injection technique (II). Acta Physiologica Scandinavica 1979;106(4) 425-430.

[42] Bill A. Blood circulation and fluid dynamics in the eye. Physiological Reviews 1975;55(3) 383-417.

[43] Bill A, Sperber G, Ujiie K. Physiology of the choroidal vascular bed. International Ophthalmology 1983;6(2) 101-107.

[44] Yamamoto T, Fukuda S, Obata H, Yamashita H. Electron microscopic observation of pseudopodia from choriocapillary endothelium. Japanese Journal of Ophthalmology 1994;38(2) 129-138.

[45] Guymer R, Luthert P, Bird A. Changes in Bruch's membrane and related structures with age. Progress in Retinal and Eye Research 1999;18(1) 59-90.

[46] Guymer RH, Bird AC, Hageman GS. Cytoarchitecture of Choroidal Capillary Endothelial Cells. Investigative Ophthalmology Visual Science 2004;45(6) 1660-1666.

[47] Manche EE, Korte GE. Ultrastructural evidence of remodelling in the microvasculature of the normal rabbit and human eye. Acta Anatomica 1990;138(2) 89-96.

[48] Torczynski E, Tso MO. The architecture of the choriocapillaris at the posterior pole. American Journal of Ophthalmology 1976;81(4) 428-440.

[49] Hogan MJ, Feeney L. Electron microscopy of the human choroid. III. The blood vessels. American Journal of Ophthalmology 1961;51 1084-1097.

[50] Oyster CW. The human eye. Structure and function. Sunderland (Massachusetts): Sinauer Associates; 1999.

[51] Triviño A, de Hoz R, Rojas B, Salazar JJ, Ramírez AI, Gallego B, Ramírez JM. The human choroid posseses substance $\mathrm{P}$ and calcitonine gene-related peptide intrinsic neurons. Acta Ophthalmologica 2009;87 (s244). 
[52] de Hoz R, Ramírez AI, Salazar JJ, Rojas B, Ramírez JM, Triviño A. Substance P and calcitonin gene-related peptide intrinsic choroidal neurons in human choroidal wholemounts. Histology and Histopathology 2008;23(10) 1249-1258.

[53] Ruskell GL. Facial parasympathetic innervation of the choroidal blood vessels in monkeys. Experimental Eye Research 1971;12(2) 166-172.

[54] De Stefano ME, Mugnaini E. Fine structure of the choroidal coat of the avian eye. Vascularization, supporting tissue and innervation. Anatomy and Embryology 1997;195(5) 393-418.

[55] Rojas B, Ramírez AI, Salazar JJ, de Hoz R, Redondo A, Raposo R, Mendez T, Tejerina T, Triviño A, Ramírez JM. Low-dosage statins reduce choroidal damage in hypercholesterolemic rabbits. Acta Ophthalmologica 2011;89(7) 660-669.

[56] Pournaras CJ, Rungger-Brändle E, Riva CE, Hardarson SH, Stefansson E. Regulation of retinal blood flow in health and disease. Progress in Retinal and Eye Research 2008;27(3) 284-330.

[57] Feeney L, Hogan MJ. Electron microscopy of the human choroid. I. Cells and supporting structure. American Journal of Ophthalmology 1961;51 1057-1072.

[58] Cavallotti C, Corrado BG, Feher J. The human choriocapillaris: evidence for an intrinsic regulation of the endothelium? Journal of Anatomy 2005;206(3) 243-247.

[59] Le Beux YJ, Willemot J. Actin- and myosin-like filaments in rat brain pericytes. Anatomical Record 1978;190(4) 811-826.

[60] Nickla DL, Wallman J. The multifunctional choroid. Progress in Retinal and Eye Research 2010;29(2) 144-168.

[61] Alm A, Bill A, Young FA. The effects of pilocarpine and neostigmine on the blood flow through the anterior uvea in monkeys. A study with radioactively labelled microspheres. Experimental Eye Research 1973;15(1) 31-36.

[62] Alm A, Bill A. Ocular and optic nerve blood flow at normal and increased intraocular pressures in monkeys (Macaca irus): a study with radioactively labelled microspheres including flow determinations in brain and some other tissues. Experimental Eye Research 1973;15(1) 15-29.

[63] Alm A, Bill A. Blood flow and oxygen extraction in the cat uvea at normal and high intraocular pressures. Acta Physiologica Scandinavica 1970;80(1) 19-28.

[64] Parver LM, Auker CR, Carpenter DO. The stabilizing effect of the choroidal circulation on the temperature environment of the macula. Retina 1982;2(2) 117-120.

[65] Parver LM, Auker CR, Carpenter DO. Choroidal blood flow. III. Reflexive control in human eyes. Archives of Ophthalmology 1983;101(10) 1604-1606.

[66] Parver LM, Auker CR, Carpenter DO, Doyle T. Choroidal blood flow II. Reflexive control in the monkey. Archives of Ophthalmology 1982;100(8) 1327-1330.

[67] Yu DY, Alder VA, Cringle SJ, Brown MJ. Choroidal blood flow measured in the dog eye in vivo and in vitro by local hydrogen clearance polarography: validation of a technique and response to raised intraocular pressure. Experimental Eye Research 1988;46(3) 289303.

[68] Friedman E. Choroidal blood flow. Pressure-flow relationships. Archives of Ophthalmology 1970;83(1) 95-99. 
[69] Dollery CT, Bulpitt CJ, Kohner EM. Oxygen supply to the retina from the retinal and choroidal circulations at normal and increased arterial oxygen tensions. Investigative Ophthalmology 1969;8(6) 588-594.

[70] Flower RW, Fryczkowski AW, McLeod DS. Variability in choriocapillaris blood flow distribution. Investigative Ophthalmology \& Visual Science 1995;36(7) 1247-1258.

[71] Kiel JW, Shepherd AP. Autoregulation of choroidal blood flow in the rabbit. Investigative Ophthalmology \& Visual Science 1992;33(8) 2399-2410.

[72] Ramírez JM, Ramírez AI, Salazar JJ, de Hoz R, Rojas B, Triviño A. Anatomofisiología de la úvea posterior: coroides. In: Monés J, Gómez-Ulla F. (ed) Degeneración macular asociada a la edad. Barcelona: Prous Science; 2005. p1-28.

[73] Steinle JJ, Pierce JD, Clancy RL, G. Smith P. Increased Ocular Blood Vessel Numbers and Sizes Following Chronic Sympathectomy in Rat. Experimental Eye Research 2002;74(6) 761-768.

[74] Schmidt RE, Beaudet LN, Plurad SB, Dorsey DA. Axonal cytoskeletal pathology in aged and diabetic human sympathetic autonomic ganglia. Brain Research 1997;769(2) 375383.

[75] Ishikawa S, Bensaoula T, Uga S, Mukuno K. Electron-microscopic study of iris nerves and muscles in diabetes. Ophthalmologica. 1985;191(3) 172-183.

[76] Fulk GW, Bower A, McBride K, Boatright R. Sympathetic denervation of the iris dilator in noninsulin-dependent diabetes. Optometry and Vision Science 1991;68(12) 954-956.

[77] Ernest JT. Regulatory mechanism of the choroidal vasculature in health and disease. In: Tso MOM. (ed) Retinal diseases: biomedical foundations and clinical management Philadelphia: JB Lippincott.; 1988. p125-130.

[78] Grunwald JE, Hariprasad SM, DuPont J. Effect of aging on foveolar choroidal circulation. Archives of Ophthalmology 1998;116(2) 150-154.

[79] Grunwald JE, Metelitsina TI, Dupont JC, Ying GS, Maguire MG. Reduced foveolar choroidal blood flow in eyes with increasing AMD severity. Investigative Ophthalmology \& Visual Science 2005;46(3) 1033-1038.

[80] Yorek MA, Coppey LJ, Gellett JS, Davidson EP. Sensory nerve innervation of epineurial arterioles of the sciatic nerve containing calcitonin gene-related peptide: effect of streptozotocin-induced diabetes. Experimental Diabesity Research 2004;5(3) 187-193.

[81] Park JG, Oh GT. The role of peroxidases in the pathogenesis of atherosclerosis. BMB Reports 2011;44(8) 497-505.

[82] Wittchen ES. Endothelial signaling in paracellular and transcellular leukocyte transmigration. Frontiers in Bioscience 2009;14 2522-2545.

[83] Shibata N, Glass CK. Regulation of macrophage function in inflammation and atherosclerosis. Journal of Lipid Research 2009;50 SS 277-81.

[84] Madamanchi NR, Vendrov A, Runge MS. Oxidative stress and vascular disease. Arteriosclerosis, Thrombosis, and Vascular Biology 2005;25(1) 29-38.

[85] Glass CK, Witztum JL. Atherosclerosis. The road ahead. Cell 2001;104(4) 503-516.

[86] Taniyama Y, Griendling KK. Reactive oxygen species in the vasculature: molecular and cellular mechanisms. Hypertension 2003;42(6) 1075-1081. 
[87] Libby P, Okamoto Y, Rocha VZ, Folco E. Inflammation in atherosclerosis: transition from theory to practice. Circulation Journal 2010;74(2) 213-220.

[88] Rudijanto A. The role of vascular smooth muscle cells on the pathogenesis of atherosclerosis. Acta Medica Indonesiana 2007;39(2) 86-93.

[89] Grote K, Flach I, Luchtefeld M, Akin E, Holland SM, Drexler H, Schieffer B. Mechanical stretch enhances mRNA expression and proenzyme release of matrix metalloproteinase-2 (MMP-2) via NAD(P)H oxidase-derived reactive oxygen species. Circulation Research 2003;92(11) 80-6.

[90] De Keulenaer GW, Ushio-Fukai M, Yin Q, Chung AB, Lyons PR, Ishizaka N, Rengarajan K, Taylor WR, Alexander RW, Griendling KK. Convergence of redox-sensitive and mitogen-activated protein kinase signaling pathways in tumor necrosis factor-alphamediated monocyte chemoattractant protein-1 induction in vascular smooth muscle cells. Arteriosclerosis, Thrombosis, and Vascular Biology 2000;20(2) 385-391.

[91] von Harsdorf R, Li PF, Dietz R. Signaling pathways in reactive oxygen species-induced cardiomyocyte apoptosis. Circulation 1999;99(22) 2934-2941.

[92] Zhu P, Dettmann ES, Resink TJ, Luscher TF, Flammer J, Haefliger IO. Effect of Ox-LDL on endothelium-dependent response in pig ciliary artery: prevention by an ET(A) antagonist. Investigative Ophthalmology \& Visual Science 1999;40(5) 1015-1020.

[93] Tanner FC, Noll G, Boulanger CM, Luscher TF. Oxidized low density lipoproteins inhibit relaxations of porcine coronary arteries. Role of scavenger receptor and endothelium-derived nitric oxide. Circulation 1991;83(6) 2012-2020.

[94] Anderson TJ, Meredith IT, Yeung AC, Frei B, Selwyn AP, Ganz P. The effect of cholesterol-lowering and antioxidant therapy on endothelium-dependent coronary vasomotion. New England Journal of Medicine 1995;332(8) 488-493.

[95] Feron O, Dessy C, Moniotte S, Desager JP, Balligand JL. Hypercholesterolemia decreases nitric oxide production by promoting the interaction of caveolin and endothelial nitric oxide synthase. Journal of Clinical Investigation 1999;103(6) 897-905.

[96] Donners MMPC, Heeneman S, Daemen MJAP. Models of atherosclerosis and transplant arteriosclerosis: the quest for the best. Drug Discovery Today: Disease Models 2004;1(3) 257-263.

[97] Zadelaar S, Kleemann R, Verschuren L, de Vries-Van der Weij J, van der Hoorn J, Princen HM, Kooistra T. Mouse Models for Atherosclerosis and Pharmaceutical Modifiers. Arteriosclerosis, Thrombosis, and Vascular Biology 2007;27(8) 1706-1721.

[98] Nakashima Y, Plump AS, Raines EW, Breslow JL, Ross R. ApoE-deficient mice develop lesions of all phases of atherosclerosis throughout the arterial tree. Arteriosclerosis and Thrombosis 1994;14(1) 133-140.

[99] Jawien J. The role of an experimental model of atherosclerosis: apoE-knockout mice in developing new drugs against atherogenesis. Current Pharmaceutical Biotechnology 2012; [Epub ahead of print] PMID: 22280417

[100] Davignon J. Apolipoprotein E and atherosclerosis: beyond lipid effect. Arteriosclerosis, Thrombosis, and Vascular Biology 2005;25(2) 267-269.

[101] Ali K, Middleton M, Pure E, Rader DJ. Apolipoprotein E suppresses the type I inflammatory response in vivo. Circulation Research 2005;97(9) 922-927. 
[102] Grainger DJ, Reckless J, McKilligin E. Apolipoprotein E modulates clearance of apoptotic bodies in vitro and in vivo, resulting in a systemic proinflammatory state in apolipoprotein E-deficient mice. Journal of Immunology 2004;173(10) 6366-6375.

[103] Knowles JW, Maeda N. Genetic modifiers of atherosclerosis in mice. Arteriosclerosis, Thrombosis, and Vascular Biology 2000;20(11) 2336-2345.

[104] Ishibashi S, Goldstein JL, Brown MS, Herz J, Burns DK. Massive xanthomatosis and atherosclerosis in cholesterol-fed low density lipoprotein receptor-negative mice. Journal of Clinical Investigation 1994;93(5) 1885-1893.

[105] van Vlijmen BJ, van den Maagdenberg AM, Gijbels MJ, van der Boom H, HogenEsch H, Frants RR, Hofker MH, Havekes LM. Diet-induced hyperlipoproteinemia and atherosclerosis in apolipoprotein E3-Leiden transgenic mice. Journal of Clinical Investigation 1994;93(4) 1403-1410.

[106] Jacobsson L. Comparison of experimental hypercholesterolemia and atherosclerosis in Gottingen mini-pigs and Swedish domestic swine. Atherosclerosis 1986;59(2) 205-213.

[107] Turk JR, Henderson KK, Vanvickle GD, Watkins J, Laughlin MH. Arterial endothelial function in a porcine model of early stage atherosclerotic vascular disease. International Journal of Experimental Pathology 2005;86(5) 335-345.

[108] Kamimura R, Miura N, Suzuki S. The hemodynamic effects of acute myocardial ischemia and reperfusion in Clawn miniature pigs. Experimental Animals 2003;52(4) 335338.

[109] Liang Y, Zhu H, Friedman MH. The correspondence between coronary arterial wall strain and histology in a porcine model of atherosclerosis. Physics in Medicine and Biology 2009;54(18) 5625-5641.

[110] Thim T. Human-like atherosclerosis in minipigs: a new model for detection and treatment of vulnerable plaques. Danish Medical Bulletin 2010;57(7) B4161.

[111] Miyoshi N, Horiuchi M, Inokuchi Y, Miyamoto Y, Miura N, Tokunaga S, Fujiki M, Izumi Y, Miyajima H, Nagata R, Misumi K, Takeuchi T, Tanimoto A, et al. Novel microminipig model of atherosclerosis by high fat and high cholesterol diet, established in Japan. In Vivo 2010;24(5) 671-680.

[112] Kawaguchi H, Miyoshi N, Miura N, Fujiki M, Horiuchi M, Izumi Y, Miyajima H, Nagata R, Misumi K, Takeuchi T, Tanimoto A, Yoshida H. Microminipig, a non-rodent experimental animal optimized for life science research:novel atherosclerosis model induced by high fat and cholesterol diet. Journal of Pharmacological Sciences 2011;115(2) 115-121.

[113] Stoletov K, Fang L, Choi SH, Hartvigsen K, Hansen LF, Hall C, Pattison J, Juliano J, Miller ER, Almazan F, Crosier P, Witztum JL, Klemke RL, et al. Vascular lipid accumulation, lipoprotein oxidation, and macrophage lipid uptake in hypercholesterolemic zebrafish. Circulation Research 2009;104(8) 952-960.

[114] Fang L, Harkewicz R, Hartvigsen K, Wiesner P, Choi SH, Almazan F, Pattison J, Deer E, Sayaphupha T, Dennis EA, Witztum JL, Tsimikas S, Miller YI. Oxidized cholesteryl esters and phospholipids in zebrafish larvae fed a high cholesterol diet: macrophage binding and activation. Journal of Biological Chemistry 2010;285(42) 32343-32351. 
[115] Fang L, Green SR, Baek JS, Lee SH, Ellett F, Deer E, Lieschke GJ, Witztum JL, Tsimikas S, Miller YI. In vivo visualization and attenuation of oxidized lipid accumulation in hypercholesterolemic zebrafish. Journal of Clinical Investigation 2011;121(12) 4861-4869.

[116] Yanni AE. The laboratory rabbit: an animal model of atherosclerosis research. Laboratory Animals 2004;38(3) 246-256.

[117] Daugherty A, Zweifel BS, Schonfeld G. Probucol attenuates the development of aortic atherosclerosis in cholesterol-fed rabbits. British Journal of Pharmacology 1989;98(2) 612-618.

[118] Del Rio M, Chulia T, Merchan-Perez A, Remezal M, Valor S, Gonzalez J, Gutierrez JA, Contreras JA, Lasuncion MA, Tejerina T. Effects of indapamide on atherosclerosis development in cholesterol-fed rabbits. Journal of Cardiovascular Pharmacology 1995;25(6) 973-978.

[119] Huff MW, Carroll KK. Effects of dietary protein on turnover, oxidation, and absorption of cholesterol, and on steroid excretion in rabbits. Journal of Lipid Research 1980;21(5) 546-548.

[120] Zauberman H, Livni N. Experimental vascular occlusion in hypercholesterolemic rabbits. Investigative Ophthalmology \& Visual Science 1981;21(2) 248-255.

[121] Finking G, Hanke H. Nikolaj Nikolajewitsch Anitschkow (1885-1964) established the cholesterol-fed rabbit as a model for atherosclerosis research. Atherosclerosis 1997;135(1) 1-7.

[122] Redgrave TG, Dunne KB, Roberts DCK, West CE. Chylomicron metabolism in rabbits fed diets with or without added cholesterol. Atherosclerosis 1976;24(3) 501-508.

[123] Chapman MJ. Animal lipoproteins: chemistry, structure, and comparative aspects. Journal of lipid research 1980;21(7) 789-853.

[124] Roth RI, Gaubatz JW, Gotto AM,Jr, Patsch JR. Effect of cholesterol feeding on the distribution of plasma lipoproteins and on the metabolism of apolipoprotein $\mathrm{E}$ in the rabbit. Journal of Lipid Research 1983;24(1) 1-11.

[125] Reddy C, Stock EL, Mendelsohn AD, Nguyen HS, Roth SI, Ghosh S. Pathogenesis of experimental lipid keratopathy: corneal and plasma lipids. Investigative Ophthalmology \& Visual Science 1987;28(9) 1492-1496.

[126] Holm P, Andersen HL, Arroe G, Stender S. Gender gap in aortic cholesterol accumulation in cholesterol-clamped rabbits: role of the endothelium and mononuclearendothelial cell interaction. Circulation 1998;98(24) 2731-2737.

[127] Ponraj D, Makjanic J, Thong PS, Tan BK, Watt F. The onset of atherosclerotic lesion formation in hypercholesterolemic rabbits is delayed by iron depletion. FEBS Letters 1999;459(2) 218-222.

[128] Hanyu M, Kume N, Ikeda T, Minami M, Kita T, Komeda M. VCAM-1 expression precedes macrophage infiltration into subendothelium of vein grafts interposed into carotid arteries in hypercholesterolemic rabbits--a potential role in vein graft atherosclerosis. Atherosclerosis 2001;158(2) 313-319.

[129] Kálmán J, Kudchodkar BJ, Krishnamoorthy R, Dory L, Lacko AG, Agarwal N. High cholesterol diet down regulates the activity of activator protein-1 but not nuclear factorkappa B in rabbit brain. Life Sciences 2001;68(13) 1495-1503. 
[130] de la Peña NC, Sosa-Melgarejo JA, Ramos RR, Méndez JD. Inhibition of platelet aggregation by putrescine, spermidine, and spermine in hypercholesterolemic rabbits. Archives of Medical Research 2000;31(6) 546-550.

[131] Francois J, Neetens A. Vascular manifestations of experimental hypercholesteraemia in rabbits. Angiologica 1966;3(1) 1-20.

[132] Amaratunga A, Abraham CR, Edwards RB, Sandell JH, Schreiber BM, Fine RE. Apolipoprotein $\mathrm{E}$ is synthesized in the retina by Muller glial cells, secreted into the vitreous, and rapidly transported into the optic nerve by retinal ganglion cells. Journal of Biological Chemistry 1996;271(10) 5628-5632.

[133] Sebesteny A, Sheraidah GA, Trevan DJ, Alexander RA, Ahmed AI. Lipid keratopathy and atheromatosis in an SPF laboratory rabbit colony attributable to diet. Laboratory Animals 1985;19(3) 180-188.

[134] Yamamoto T, Bishop RW, Brown MS, Goldstein JL, Russell DW. Deletion in cysteinerich region of LDL receptor impedes transport to cell surface in WHHL rabbit. Science 1986;232(4755) 1230-1237.

[135] Shiomi M, Ito T. The Watanabe heritable hyperlipidemic (WHHL) rabbit, its characteristics and history of development: A tribute to the late Dr. Yoshio Watanabe. Atherosclerosis 2009;207(1) 1-7.

[136] Watanabe Y. Serial inbreeding of rabbits with hereditary hyperlipidemia (WHHLrabbit). Atherosclerosis 1980;36(2) 261-268.

[137] Steen H, Lima JA, Chatterjee S, Kolmakova A, Gao F, Rodriguez ER, Stuber M. Highresolution three-dimensional aortic magnetic resonance angiography and quantitative vessel wall characterization of different atherosclerotic stages in a rabbit model. Investigative Radiology 2007;42(9) 614-621.

[138] Ogawa M, Ishino S, Mukai T, Asano D, Teramoto N, Watabe H, Kudomi N, Shiomi M, Magata Y, Iida H, Saji H. (18)F-FDG accumulation in atherosclerotic plaques: immunohistochemical and PET imaging study. Journal of Nuclear Medicine 2004;45(7) 12451250.

[139] Iwata A, Miura S, Imaizumi S, Zhang B, Saku K. Measurement of atherosclerotic plaque volume in hyperlipidemic rabbit aorta by intravascular ultrasound. Journal of Cardiology 2007;50(4) 229-234.

[140] Sadowitz B, Maier KG, Gahtan V. Basic science review: Statin therapy--Part I: The pleiotropic effects of statins in cardiovascular disease. Vascular and Endovascular Surgery 2010;44(4) 241-251.

[141] Sadowitz B, Seymour K, Costanza MJ, Gahtan V. Statin therapy--Part II: Clinical considerations for cardiovascular disease. Vascular and Endovascular Surgery 2010;44(6) 421-433.

[142] van der Most PJ, Dolga AM, Nijholt IM, Luiten PGM, Eisel ULM. Statins: Mechanisms of neuroprotection. Progress in Neurobiology 2009;88(1) 64-75.

[143] Zhou Q, Liao JK. Statins and cardiovascular diseases: from cholesterol lowering to pleiotropy. Current Pharmaceutical Design 2009;15(5) 467-478.

[144] Zhou Q, Liao JK. Pleiotropic effects of statins. - Basic research and clinical perspectives -. Circulation Journal 2010;74(5) 818-826. 
[145] Botti RE, Triscari J, Pan HY, Zayat J. Concentrations of pravastatin and lovastatin in cerebrospinal fluid in healthy subjects. Clinical Neuropharmacology 1991;14(3) 256-261.

[146] Wang CY, Liu PY, Liao JK. Pleiotropic effects of statin therapy: molecular mechanisms and clinical results. Trends in Molecular Medicine 2008;14(1) 37-44.

[147] Athyros VG, Kakafika AI, Tziomalos K, Karagiannis A, Mikhailidis DP. Pleiotropic effects of statins--clinical evidence. Current Pharmaceutical Design 2009;15(5) 479-489.

[148] Rikitake Y, Kawashima S, Takeshita S, Yamashita T, Azumi H, Yasuhara M, Nishi H, Inoue N, Yokoyama M. Anti-oxidative properties of fluvastatin, an HMG-CoA reductase inhibitor, contribute to prevention of atherosclerosis in cholesterol-fed rabbits. Atherosclerosis 2001;154(1) 87-96.

[149] Porter KE, Naik J, Turner NA, Dickinson T, Thompson MM, London NJ. Simvastatin inhibits human saphenous vein neointima formation via inhibition of smooth muscle cell proliferation and migration. Journal of Vascular Surgery 2002;36(1) 150-157.

[150] Mitani H, Egashira K, Kimura M. HMG-CoA reductase inhibitor, fluvastatin, has cholesterol-lowering independent "direct" effects on atherosclerotic vessels in high cholesterol diet-fed rabbits. Pharmacological Research 2003;48(5) 417-427.

[151] Hall NF, Gale CR, Syddall H, Phillips DI, Martyn CN. Risk of macular degeneration in users of statins: cross sectional study. British Medical Journal 2001;323(7309) 375-376.

[152] McCarty CA, Mukesh BN, Guymer RH, Baird PN, Taylor HR. Cholesterol-lowering medications reduce the risk of age-related maculopathy progression. Medical Journal of Australia 2001;175(6) 340.

[153] Yamada K, Sakurai E, Itaya M, Yamasaki S, Ogura Y. Inhibition of Laser-Induced Choroidal Neovascularization by Atorvastatin by Downregulation of Monocyte Chemotactic Protein-1 Synthesis in Mice. Investigative Ophthalmology Visual Science 2007;48(4) 1839-1843.

[154] Yamakawa K, Bhutto IA, Lu Z, Watanabe Y, Amemiya T. Retinal vascular changes in rats with inherited hypercholesterolemia--corrosion cast demonstration. Current Eye Research 2001;22(4) 258-265.

[155] Ong JM, Zorapapel NC, Rich KA, Wagstaff RE, Lambert RW, Rosenberg SE, Moghaddas F, Pirouzmanesh A, Aoki AM, Kenney MC. Effects of cholesterol and apolipoprotein $\mathrm{E}$ on retinal abnormalities in ApoE-deficient mice. Investigative Ophthalmology \& Visual Science 2001;42(8) 1891-1900.

[156] Kouchi M, Ueda Y, Horie H, Tanaka K. Ocular lesions in Watanabe heritable hyperlipidemic rabbits. Veterinary Ophthalmology 2006;9(3) 145-148.

[157] Triviño A, Ramírez AI, Salazar JJ, de Hoz R, Rojas B, Padilla E, Tejerina T, Ramírez JM. A cholesterol-enriched diet induces ultrastructural changes in retinal and macroglial rabbit cells. Experimental Eye Research 2006;83(2) 357-366.

[158] Ramírez AI, Salazar JJ, de Hoz R, Rojas B, Ruiz E, Tejerina T, Ramírez JM, Triviño A. Macroglial and retinal changes in hypercholesterolemic rabbits after normalization of cholesterol levels. Experimental Eye Research 2006;83(6) 1423-1438.

[159] Shibata M, Sugiyama T, Hoshiga M, Hotchi J, Okuno T, Oku H, Hanafusa T, Ikeda T. Changes in optic nerve head blood flow, visual function, and retinal histology in hypercholesterolemic rabbits. Experimental Eye Research 2011;93(6) 818-824. 
[160] Triviño A, Rojas B, Ramírez AI, Salazar JJ, de Hoz R, Ramajo M, Redondo S, NavarroDorado J, Tejerina T, Ramírez JM. Low-dosage statins reduce choroidal damage in hypercholesterolemic rabbits. Acta Ophthalmologica 2011;89(7) 660-669.

[161] Torres RJ, Muccioli C, Maia M, Noronha L, Luchini A, Alessi A, Olandoski M, Farah ME, Precoma DB. Sclerochorioretinal abnormalities in hypercholesterolemic rabbits treated with rosiglitazone. Ophthalmic Surgery, Lasers \& Imaging 2010;41(5) 562-571.

[162] Topper JN, Gimbrone MA,Jr. Blood flow and vascular gene expression: fluid shear stress as a modulator of endothelial phenotype. Molecular Medicine Today 1999;5(1) 4046.

[163] Wu CC, Chang SW, Chen MS, Lee YT. Early change of vascular permeability in hypercholesterolemic rabbits. Arteriosclerosis, Thrombosis, and Vascular Biology 1995;15(4) 529-533.

[164] Sánchez-Pérez RM, Molto JM, Medrano V, Beltrán I, Diaz-Marín C. Atherosclerosis and brain circulation. Revista de Neurologia 1999;28(11) 1109-1115.

[165] Darblade B, Caillaud D, Poirot M, Fouque M, Thiers J, Rami J, Bayard F, Arnal J. Alteration of plasmalemmal caveolae mimics endothelial dysfunction observed in atheromatous rabbit aorta. Cardiovascular Research 2001;50(3) 566-576.

[166] Hardin CD, Vallejo J. Caveolins in vascular smooth muscle: form organizing function. Cardiovascular Research 2006;69(4) 808-815.

[167] Drab M, Verkade P, Elger M, Kasper M, Lohn M, Lauterbach B, Menne J, Lindschau C, Mende F, Luft FC, Schedl A, Haller H, Kurzchalia TV. Loss of caveolae, vascular dysfunction, and pulmonary defects in caveolin-1 gene-disrupted mice. Science 2001;293(5539) 2449-2452.

[168] Bosch M, Mari M, Gross SP, Fernandez-Checa JC, Pol A. Mitochondrial cholesterol: a connection between caveolin, metabolism, and disease. Traffic 2011;12(11) 1483-1489.

[169] Lin WW, Lin YC, Chang TY, Tsai SH, Ho HC, Chen YT, Yang VC. Caveolin-1 expression is associated with plaque formation in hypercholesterolemic rabbits. Journal of Histochemistry and Cytochemistry 2006;54(8) 897-904.

[170] Xu Y, Buikema H, van Gilst WH, Henning RH. Caveolae and endothelial dysfunction: filling the caves in cardiovascular disease. European Journal of Pharmacology 2008;585(2-3) 256-260.

[171] Malinow MR. Experimental models of atherosclerosis regression. Atherosclerosis 1983;48(2) 105-118.

[172] Lusis AJ. Atherosclerosis. Nature 2000;407(6801) 233-241.

[173] Saso Y, Kitamura K, Yasoshima A, Iwasaki HO, Takashima K, Doi K, Morita T. Rapid induction of atherosclerosis in rabbits. Histology and Histopathology 1992;7(3) 315-320.

[174] Rodger FC. A new preparation for the study of experimental atherosclerosis progressive-regressive changes in albino rabbit iris. Experimental Eye Research 1972;14(1) 1-6.

[175] Abdulla YH, Adams CW, Morgan RS. Connective-tissue reactions to implantation of purified sterol, sterol esters, phosphoglycerides, glycerides and free fatty acids. Journal of Pathology and Bacteriology 1967;94(1) 63-71.

[176] Henney AM, Wakeley PR, Davies MJ, Foster K, Hembry R, Murphy G, Humphries S. Localization of stromelysin gene expression in atherosclerotic plaques by in situ hybrid- 
ization. Proceedings of the National Academy of Sciences of the United States of America $1991 ; 88(18) 8154-8158$.

[177] Galis ZS, Sukhova GK, Lark MW, Libby P. Increased expression of matrix metalloproteinases and matrix degrading activity in vulnerable regions of human atherosclerotic plaques. Journal of Clinical Investigation 1994;94(6) 2493-2503.

[178] McGwin G,Jr, Xie A, Owsley C. The use of cholesterol-lowering medications and agerelated macular degeneration. Ophthalmology 2005;112(3) 488-494.

[179] Jukema JW, Bruschke AVG, van Boven AJ, Reiber JHC, Bal ET, Zwinderman AH, Jansen H, Boerma GJM, van Rappard FM, Lie KI. Effects of Lipid Lowering by Pravastatin on Progression and Regression of Coronary Artery Disease in Symptomatic Men With Normal to Moderately Elevated Serum Cholesterol Levels : The Regression Growth Evaluation Statin Study (REGRESS). Circulation 1995;91(10) 2528-2540.

[180] Corsini A, Pazzucconi F, Pfister P, Paoletti R, Sirtori CR. Inhibitor of proliferation of arterial smooth-muscle cells by fluvastatin. Lancet 1996;348(9041) 1584.

[181] Lee TM, Lin MS, Chou TF, Tsai CH, Chang NC. Effect of pravastatin on left ventricular mass by activation of myocardial K ATP channels in hypercholesterolemic rabbits. Atherosclerosis 2004;176(2) 273-278.

[182] Kurokawa J, Hayashi K, Toyota Y, Shingu T, Shiomi M, Kajiyama G. High dose of fluvastatin sodium (XU62-320), a new inhibitor of 3-hydroxy-3-methylglutaryl coenzyme A reductase, lowers plasma cholesterol levels in homozygous Watanabe-heritable hyperlipidemic rabbits. Biochimica et Biophysica Acta 1995;1259(1) 99-104.

[183] Taggart MJ. Smooth muscle excitation-contraction coupling: a role for caveolae and caveolins? News in Physiological Sciences 2001;16 61-65.

[184] Poche R, de Mello Mattos CM, Rembarz HW, Stoepel K. The mitochondrial-myofibril ratio in rat myocardial cells in hypertensive cardiac hypertrophy. Virchows Archives A: Pathology.1968;344(1) 100-110.

[185] Simon DK, Johns DR. Mitochondrial disorders: clinical and genetic features. Annual Review of Medicine 1999;50 111-127. 